Update Report on Fracture Flow in

Saturated Tuff: Dynamic Transport Task

for the Nevada Nuclear Waste Investigations

D. R. Janecky

R. S. Rundberg

M. Ott

A. Mitchell 


\title{
Update Report on Fracture flow in Saturated Tuff: \\ Dynamic Transport Task fos the Nevada Nuclear Waste Investigations \\ by
}

D. R. Janecky, R. S. Rundberg. M. Ott, and A. Mitchell

\begin{abstract}
This report summarizes the results of continuing experiments on the behavior of tracers during fracture flow in saturated, welded tuff. These experiments were completed during the past year as part of the Dynamic Transport Task of geochemical investigations for the Yucca Mountain Project sponsored by the IIS Department of Energy. These experiments are designed to investigate the effects of fluid movement in fractures when coupled with matrix diffusion and sorption but isolated from the eifects of capillary suction and two-phase flow characteristic of unsaturated conditions. The experiments reported here aré continuations of experimental efforts reported previously.

The behavior of three tracers [HTO (tritiated water), $\mathrm{TcO}_{4}^{-}$(pertechnetate), and sulforhodamine B dye] have been investigated during flow through a saturated column of densely welded tuff from the Topopah Spring Member of the Paintbrush Tuff, Yucca Mountain, Nye County, southern Nevada. This rock column is cut by a natural fracture network similar to networks characteized elsewhere in these tuffs. Experimental problems in HTO experiments make interpretation difficult. However, it appears that breakthrough occurs rapidly, consistent with the other tracer hehavior. Recoveries for HTO are between 60 and $70 \%$. The other tracers exhibit higher recoveries than HTO. This is interpreted as a function of size exclusion of molecular species from an increasing proportion of the matrix pores for pertechnetate and sulforhodamine B dye. Pertechnetate may also be affected by anion exclusion and sorption, but these effects have not yet been quantified. Modeling the experiments by using a formulation for a single, parallel-sided fracture in a porous rock matrix and appropriate values for adjustable parameters produces consistent elution curves and aids in interpreting HTO experimental data.
\end{abstract}

\section{INTRODUCTION}

The Yucca Mountain Project (YMP) of the US Department of Energy is studying the suitability of the Yucca Mountain area, Nye County, southern Nevada, as a potential geological repository for highlevel nuclear waste. The mountain is composed of numerous strata of ash-flow and ash-fall tuffs, with a stratigraphic thickness exceeding $3000 \mathrm{~m}$ in Yucca Mountain and Crater Flat (Snyder and Carr, 1982). The proposed repository location is in densely welded, devitrified tuff of the Topopah Springs Member of the Paintbrush Tuff. 
The Yucca Mountain site has unique features with respect to evaluating hydrologic transport and isolation of waste radionuclides. The proposed repository horizon is above the water table, and the matrix of the surrounding host rock has significant porosity (Peters et al., 1984). Abundant secondary minerals, such as the zeolites clinoptilolite, heulandite, and mordenite as well as smectite clays and calcite, are found in the rock matrix and lining fractures of rocks beneath and hydrologically down-gradient of the potential repository horizon (Vaniman et al., 1984). These minerals have significant capabilities to sorb dissolved species from solution, including waste radionuclides (Rundberg, 1984; Thomas, 1985). The unsaturated matrix with high porosity will tend to draw water and dissolved radionuclides from the fractures into the pore space of the surrounding tuff (Travis et al., 1984), thus providing favorable conditions for limiting transport by impeding flow and by increasing access to sorbing minerals (Neretnicks, 1980).

The abundance of fractures in the tuffs of Yucca Mountain has been documented in the reports of the US Geological Survey (USGS) (Montager and Wilson, 1984; Spengler and Chornack, 1984; Bentley, 1984; Craig et al., 1983; Geohydrologic, 1983; Thordarson, 1983). In addition, large faults are known to cut the section, intersecting welded and bedded tuff strata in both unsaturated and saturated zones (Scott and Bonk, 1984). Hydrologic tests have found the more permeable zones are in the welded tuff strata, presumably as a result of abundant cooling joints in the welded tuff zones (Winnograd and Thordarson, 1975). Zones below the present water table have significant components of both fracture and matrix permeability (Scott et al., 1983). The potential repository horizon is above the water table at present, and the arid climate of southern Nevada will prohably lessen the likelihood of situations that would result in saturated conditions in the repository zone. However, in assessing the overall performance of a repository, the consequences of future geologic events that lead to saturation of the fractures and surrounding rocks must be considered. In addition, the presence of alteration minerals in faults and fractures, such as zeolites, clays, and carbonates, suggests that there has been water in the fractures at some time (Arney-Carlos, 1985). These complexities require that the effects of fracture flow on aqueous transport of radionuclides be thoroughly investigated.

Modeling the hydrology and transport of contaminants in materials with significant fracture perrneability is difficult for several reasons: (1) the hydrologic properties of the media become heterogeneous and anisotropic, and (2) the distribution of component phases of rocks, which have varying sorptive or reactive 
characteristics, becomes heterogenotis relative to flow pathways. Thus, standard simplifying assumptions about homogeneous porous flow are not valid, and relationships between chemical measures, such as sorption ratio and breakthrough or retention volumes for radionuclides, are not simple. Thus, modeling requires development and validation of three dimensional heterogeneous transport models. The extreme opposite of assuming homogeneous porous flow is to assume isolated fracture flow. Models that assume only fracture flow limit sorption of radionuclides to minerals exposed on fracture surfacess. This results in retardation factors that are extremely close to 1.0 implying limited adsorption properties. This latter approach, whice conservative, is as unrealistic as the homogeneous porous flow model for Yucca Mountain because demonstrated permeability in tuffs is not limited to either fractures or matrix pores. Thus, the abundant zeolites and clays, which are excellent adsorbers and cation exchangers, are accessible. This critical access may significantly retard radionuclide mobility.

A central question examined by our research effort is the extent to which interchange between fracture flow and porous matrix flow occurs in samples of densely welded tuff from Yucca Mountain. Experiments are being conducted to determine not only geochemical transport of radionuclides in heterogeneous media but also hydrologic flow and properties. Thus, combined effects of fracture flow, matrix diffusion in both connected porosity and dead-end pores, and accessibility of sorbing minerals in each environment are being examined. Basic experimental data provide a basis for theoretical modeling of the interplay between physical/hydrologic processes and chemical reactions in the Yucca Mountain situation. In addition, the experiments provide an empirical basis for applying laboratory data such as batch sorption $\mathrm{K}_{d} \mathrm{~s}$ to the prediction of radionuclide transport in the field. They also provide an understanding of the interplay between physical and chemical processes in the complex system presented by water movement through fractures in rock. This understanding is needed to extrapolate observations from the scale and breadth of conditions simulated in laboratory experiments to conditions in the field. This ability to extrapolate is essential; because it is nearly impossible to replicate in the laboratory, with a high degree of assurance, the conditions that exist in the field.

This report and its predecessor "Fracture Flow Under Saturated Conditions" (Rundberg et al., 1986) review results of experiments that were designed to investigate the effects of fluid movement in fractures, 
coupled with matrix diffusion and sorption but isolated from the effects of capillary suction and two-phase flow. This work is similar in concept to experiments performed by Neretnicks et al. (1984) and Moreno et al. (1985), but it specifically addresses processes occurring in Paintbrush Tuff that might affect siting and performance of a waste repository in Yucca Mountain, Nevada. These experiments collected data under carefully controlled conditions to help validate the effect of matrix diffusion on the retardation of radionuclides during transport by fracture flow. Theoretical analyses indicate that matrix diffusion may be beneficial in mitigating radionuclide migration. However, experimental validation is necessary for site-specific conditions because parameters such as pore tortuosity, fracture roughness, fracture coating by minerals, and matrix permeability vary with rock type and affect the transport of material in fractures. Previous experiments that involved singly fractured tuff samples have been used to examine a variety of important tracers [HTO, $\mathrm{Sr}, \mathrm{Ce}, \mathrm{TcO}_{4}^{-}, \mathrm{Ba}$, and $\mathrm{Pu}$ (Rundberg et al., 1986)]. This report presents the results of a subsequent set of experiments using a rock column cut by a fracture network.

\section{EXPERIMENTAL}

\section{A. Description of Fracture Network Sample}

The block of fractured tuff used in these experiments was collected from surface outcroppings of the Topopah Springs Member of the Paintbrush Tuff. This sample is composed of devitrified ash-flow tuff and was selected for its network of natural fractures. Its mineralogy is similar to other Topopah Springs samples used for previous fracture flow experiments (Rundberg et al., 1986).

Pictures of block faces are shown in Fig. 1. When the sample was collected, fractures in the block were filled with carbonate minerals. Such fracture cements are common constituents of surficial sarnples but absent in deeper drill core samples. After the block was partially encapsulated, the fracture carbonate cements were removed by leaching with a dilute $\mathrm{HCl}$ solution. Accessible matrix porosity and fracture network volume, $149 \mathrm{~cm}^{3}\left(21.3 \mathrm{~cm}^{3} / \mathrm{kg}\right.$ dry weight), were determined from measurements of block dry weight and total saturated weight. An estimate of the roughness and space intersected by the fracture network has been obtained by analysis of the box dimension of fractures cutting the block faces (Fig. 2); this analysis resulted in a fractal dimension of approximately $1.1\left(\mathbf{H}_{d}\right)$ (Mandelbrot, 1975; Mandelbrot 1983; Lovejoy and 
Mandelbrot, 1985; Pentland, 1984). These results are consistent with studies of fracture networks intersecting pavements in the Yucca Mountain area (Barton, 1985)'. Information received from K. Boring, Los Nlamos National Laboratory (1986).

\section{B. Apparatus}

The block of tuff was encased in a LEXAN box and sealed with SILACIC. This box was designed to eliminate leakage of solutions around the seals, but is not capable to simulating natural lithostatic or hydrostatic loads.

Tracer-loaded solutions were flowed through the fracture network sample with a SAGE syringc pump using $60-\mathrm{cm}^{3}$ syringes. The syringe pump was chosen because it could provide steady flow at low to high Iates for the large volumes and time periods necessary to obtain data for these experiments. Pressure drops across the fracture were measured by placing Kistler 4053A1 piezoresistive transducers at the enclosure's inlet and outlet ports.

\section{Methods of Measurement}

An estimate of the fracture aperture for the fracture network sample $\left(5.92 \times 10^{-5} \mathrm{~m}\right)$ was determined by establishing an initial head of $2.0 \mathrm{~m}$ of water and measuring the flow rate and pressure drop across the network at 2.0 - to $0.05-\mathrm{m}$ head. The aperture was calculated using the cubic law for fracture flow (Witherspoon et al., 1979), as previously described by Rundberg et al. (1986). This approach assumes plane sheet flow and hydraulically smooth fractures.

During a tracer injection experiment, flow rates were determined by measuring the weight loss of the supply syringe as a function of time. The effluent concentration of tracer was determined by assaying the column effluent relative to a sample of the injected solution. Specific activities for tritiated-water (HTO)spiked samples were determined by liquid scintillation counting using a Packard model 460C automatic scintillation counter. Activities of $\mathrm{Tc}^{95 m}$ were determined by standard gamma-ray counting techniques using $\mathrm{Nal}$ detectors. Sulforhodamine $\mathrm{B}$ dye concentrations were determined by comparing standard and sample absorption over the 300- to 700- $\mu \mathrm{m}$ wavelengths using a Hewlett-Packard UV/VIS spectrophotometer. 


\section{EXPERIMENTAL RESULTS}

Table I contains the relevant operating parameters for each of the fracture elutions completed on the fractured tuff network column. The results of elutions through the fractured tuff network column, as relative concentrations (concentration eluted relative to the input concentration of tracer tabulated) vs total volume eluted, are plotted in Figs. 3-8.

TABLE I. Experimental Parameters for Network Fracture Flow Tracer

Experiments Using Devitrified, Densely Welded Tuff From the Topopah

Spring Member of the Paintbrush Tuff

\begin{tabular}{cccc}
\hline Tracer & $\begin{array}{c}\text { Flow Kate } \\
(\mathrm{m} \ell / \mathrm{hr})\end{array}$ & $\begin{array}{c}\text { Concentration } \\
(\mathrm{cpm} / \mathrm{m} \ell)\end{array}$ & $\begin{array}{c}\text { Volume } \\
(\mathrm{m} \ell)\end{array}$ \\
\hline & & & \\
HTO & 0.91 & 511.55 & 43.9 \\
HTO & 0.94 & 494.80 & 44.9 \\
HTO & 0.98 & 973.70 & 51.0 \\
TcO4- & 0.94 & 3360. & 45.1 \\
TcO4- & 0.95 & 2616. & 45.5 \\
Sulforhodarnine B dye & 54.3 & & 110.4 \\
& & & \\
\hline
\end{tabular}

\section{Discussion and Theoretical Results}

\section{A. Experimental Results and Discussion}

Elution curves for pertechnetate and sulforhodamine B dye are relatively smooth and for pertechnetate, reproducible (Figs, 6-8). In contrast, HTO elution curv 28 are irregular and not reproducible (Figs. 3-5). The first two HTO experimental results indicate significarcly delayed breakthrough and jumps in tracer concentration at $\sim 175-\mathrm{cm}^{3}$ cumulative volume. The sample, which exhibits the jump in tracer concentration in both experiments, represents the first sample collected in a capped bottle rather than in an open fraction collection tube. This suggests that earlier samples have lost HTO as a result of volitilization in the fraction collector system. In contrast, the third HTO run has a smoother elution curve with a much earlier breakthrough (Fig. 5). Theoretical models of the experiments (Sec. V.B) support the interpretation that the first two experiments did not collect HTO efficiently, whereas the third experiment is a more accurate representation of HTO tracer behavior. 
Differentiation of breakthrough volumes between tracers for these experiments is not resolvable (Figs. 5-8) because of the small number of samples taken during this interval. However, calculated total elution vs injection balances for these experiments (Figs. 9-14) indicates that approximately 75, 82, and $88 \%$ of injected HTO, pertechnetate, and sulforhodamine B dye, respectively could be rapidly flushed out of the network. The approximate per cent of HTO eluted was calculated by using the third experiment to define early elution and adding the later elution of the first two experiments, thus partially accounting for the proposed evaporative loss (Figs. 3-5 and 9-11). Percentage of total tracers eluted can be qualitatively related to molecular sizes [and molecular diffusivities (Miller, 1982; Sherwood et al., 1975)], which increase from HTO to pertechnetate to sulforhodamine B dye. Thus, modeling of these experiments could provide direct information on the size, accessibility, and connectivity of matrix porosity relative to flow in the fracture network. Elution rates for all three tracers are evidently dominated by flow in the fracture network, resulting in similarly shaped elution curves following maximum eluted tracer concentrations (Figs. 3-20).

\section{B. Theoretical Results and Discussion}

A series of models have been developed to examine coupling between fracture flow and matrix diffusion in these experiments. These models assume a single parallel-sided fracture in a porous matrix (Tang, 1981) and use the parameters listed in Table II. Initial calculations were focused on pertechnetate experiments because all the necessary input data to the models was available and the experiments showed excellent reproducibility (Figs, 6-7). The first set of models used the fracture aperture $(0.00592 \mathrm{~cm})$ calculated by the cubic law for fracture flow (Witherspoon et al., 1979; Rundberg et al., 1986). Adjusting parameters within wide limits failed to result in a good fit between the model calculations (Fig. 21) and experimental results. Choosing an aperture of $0.1 \mathrm{~cm}$, however, produced a good fit to the experimental results (Fig. 22), which could be improved by slight adjustments to dispersivity (Fig. 23).

In models of the sulforhodamine B dye experiments, the diffusivity of the dye was assumed to be equivalent to pertechnetate, and flow rate and injected volume were set to match experimental conditions. The initial model did not match experimental results, but a good fit was obtained by adjusting the dispersion constant to make the longitudinal dispersivity constant (Tang, 1981) (compare Figs. 24 and 25 with Fig. 3). 
TABLE Il, Parameters Used to Model Single Fracture in a Porons Matrix for Relative Iracer Concentration Eluted as a Function of Volume Eluted

\begin{tabular}{|c|c|c|c|c|c|}
\hline Model & Tracer & $\begin{array}{l}\text { Tracer Diffusivity } \\
\left(\mathrm{cm}^{2} / \mathrm{s}\right)\end{array}$ & $\begin{array}{l}\text { Flow Rate } \\
(\mathrm{m} \ell / \mathrm{s})\end{array}$ & $\begin{array}{l}\text { Pulse Duration }{ }^{b} \\
(\mathrm{~m} \ell)\end{array}$ & Tracer $\mathrm{K}_{d}$ \\
\hline 0 & $\mathrm{TcO}_{4}^{-}$ & $0.0000151^{6}$ & 0,000253 & 43.8 & 0. \\
\hline 1 & $\mathrm{TcO}^{-}$ & 0.0000150 & 0.000253 & 43.9 & 0. \\
\hline 2 & $\mathrm{TcO}_{4}^{-}$ & 0.0000150 & 0.000253 & 43.9 & 0. \\
\hline 3 & Sulforl odamine B dye & $0.0000160^{c}$ & 0.015100 & 110.4 & 0. \\
\hline 4 & Sulforhodamine B dye & 0.0000150 & 0.015100 & 110.4 & 0. \\
\hline 5 & H'TO & $0.0000244^{d}$ & 0.000253 & 43.9 & 0. \\
\hline \multicolumn{6}{|c|}{$\begin{array}{l}a \text { Experimental parameters, } \\
{ }^{b} \text { Miller, } 1982 . \\
{ }^{c} \text { Assumed equivalent to } \mathrm{TcO}_{4}^{-} \\
{ }^{d} \text { Sherwood et al., } 1975 .\end{array}$} \\
\hline
\end{tabular}

TABLE II. Parameters Used to Model Single Fracture in a Porous Matrix for Relative

Tracer Concentration Eluted as a Function of Volume Eluted (cont)

\begin{tabular}{|c|c|c|c|c|}
\hline Model & $\begin{array}{l}\text { Dry Bulk Density } \\
\qquad\left(\mathrm{g} / \mathrm{cm}^{3}\right)\end{array}$ & $\begin{array}{l}\text { Porosity } \\
\left(\operatorname{cin}^{3} / g\right)\end{array}$ & $\begin{array}{l}\text { Dead Volume } \\
\qquad(\mathrm{m} \ell)\end{array}$ & $\begin{array}{c}\text { Dispersivity } \\
\left(\mathrm{cm}^{2} / \mathrm{s}\right)\end{array}$ \\
\hline 0 & 2.3 & 0.047 & 0.8 & 0.003 \\
\hline 1 & 2.3 & 0.047 & 0.8 & 0.003 \\
\hline 2 & 2.3 & 0.047 & 0.8 & 0.002 \\
\hline 3 & 2.3 & 0.047 & 0.8 & 0.002 \\
\hline 4 & 2.3 & 0.047 & 0.8 & 0.120 \\
\hline 5 & 2.3 & 0.047 & 0.8 & 0.002 \\
\hline \multicolumn{5}{|c|}{$\begin{array}{l}\text { a Average tufl density. } \\
b \text { Measured by change in weight of block after saturation. } \\
c \text { Measured for encapsulated block. } \\
\text { " Adjustable parameter in model. }\end{array}$} \\
\hline
\end{tabular}


TABLE II. Purameters Used to Model Single Fracture in a Porous Matrix for Relative Tracer Concentration Eluted as a Function of Volume Eluted (cont)

\begin{tabular}{|c|c|c|c|c|c|}
\hline Model & $\begin{array}{l}\text { Widtha } \\
(\mathrm{cm})\end{array}$ & $\begin{array}{l}\text { Length } \\
\quad(\mathrm{cm})\end{array}$ & $\begin{array}{l}\text { Aperture } \\
(\mathrm{cm})\end{array}$ & Constrictivity & Tortuositye \\
\hline 0 & 17.6 & 27.0 & $0.00592^{f}$ & 0.10 & 1.410 \\
\hline 1 & 17.6 & 27.0 & 0.10000 & 0.10 & 1.410 \\
\hline 2 & 17.6 & 27.0 & 0.10000 & 0.10 & 1.410 \\
\hline 3 & 17.6 & 27.0 & 0.10000 & 0.10 & 1.410 \\
\hline 4 & 17.6 & 27.0 & 0.10000 & 0.10 & 1.410 \\
\hline 5 & 17.6 & 27.0 & 0.10000 & 0.10 & 1.410 \\
\hline \multicolumn{6}{|c|}{$\begin{array}{l}a \text { Estimated from xerox pictures of block faces. } \\
b \text { Estimated from xerox pictures of block faces. } \\
\text { o Calculated from hydraulic head and flow r ite measurements or estimated (see text). } \\
{ }^{d} \text { Estimated from tortuosity and analysis of diffusion experiments } \\
\text { where constrictivity } /(\text { tortuosity) } \cong 0.05 \text {. } \\
\text { e (Walters and Kidd, } 1979) \text {. } \\
f \text { Calculated fracture aperture (see text). }\end{array}$} \\
\hline
\end{tabular}

Setting model parameters for diffusivity and experimental conditions equivalent to those of HTO experiments results in the elution curve shown in Fig. 26. This model confirms the suggestions that experimental samples (Figs. 3 and 4) lost HTO during sampling and that elution curves for all three tracers should have essentially the same shape. The model also is consistent with lower total elution of HTO (Figs. 911, also see discussion above) relative to pertechnetate and sulforhodamine B dye (Figs. 12-14). A lower maximum concentration of HTO in the model, compared to that in the third H'TO experiment (Fig. 5), may indicate that there is a significant difference in parameters between HTO and the other tracers (for example, constrictivity),

\section{Conclusions}

Breakthrough of HTO, pertechnetate, and sulforhodamine B dye occurs rapidly in these experiments. The fraction of injected tracer eluted is $\sim 75,82$, and $88 \%$ for HTO, pertechnetate, and sulforhodamine B dye, respectively. The relative differences in recovered tracer is interpreted as a function of size exclusion of molecular species from an increasing proportion of the matrix pores. Modeling the experiments by using 
a formulation for a single parallel-sided fracture in a porous rock matrix produces elution curves that are consistent with experimental results. The calculations do, however, require a significantly larger value for fracture aperture than if they were measured experimentally. Differing fracture apperatures for fluid flow analysis and tracer data have been observed proviously and were attributed to roughness of the fracture surface ('Tsang and Tsang, 1984).

This experimental program continues to demonstrate the significance of coupled fracture flow and porous matrix flow/diffusion in tuff under saturated conditions. Hydrologic/geochemical modeling of radionuclide transport for the Yucca Mountain Project must accurately account for these combined phenomenta. Modeling of the experinental results shows promise for providing well-constrained and robust-but relatively simple-formulations that can be used in site-performance assessment models. 


\section{References}

"Geohydrologic and Drill-Holo Data for Tost Well USW 11-1, Adjacent to Nevada Test Site, Nyo County, Nevada," US Geological Survey open flle report USGS-OFR-141 (1983).

B. Arney-Carlos, "Minerals in Fractures of the Unsaturated Zone from Drill Core USW-G-4, Yucca Mountain, Nye County Nevada," Los Alamos National Laboratory report LA-10415-MS (May 1985).

C. Barton, "Fractal Geometry of Two-Dimensional Fracture Networks at Yucca Mountein, Southwestern Nevada," in Proc, of Int. Symp. on Fund. Rock Joints, B. Jorkliden, Sweden, September, 15-20, 1985.

C. B. Bentley, "Geohydrologic Data for Test Well USW G-4 Yucca Mountain Area, Nye County, Nevada," US Geological Survey open file report USGS-OFR-063 (1984).

R. W. Craig, R. L. Reed, and R. W. Spengler, "Geohydrologic Data for Test Well USW H-6 Yucca Mountain Area, Nye County, Nevada," US Geological Survey open file report USGS-OFR-856 (1983).

S. Lovejoy and B. Mandelbrot, "Fractal Properties of Rain and A Fractal Model," Tellus A. 37 209-232 (1985).

B. Mandelbrot, "Stochastic Models for the Earth's Relief, the Shape and the Fractal Dimension of Coastlines, and the Number-Area Rule for Islands," Proc. Nat. Acad. Sci. USA 72, 3825-3828 (1975).

B. Mandelbrot, The Fractal Geometry of Nature (Freeman Press, San Francisco, 1983).

D. C. Miller, "Estimation of Tracer Diffusion Coefficients of Lows in Aqueous Solution," Lawrence Livermore National Laboratory report UCRL-53319 (September 1982).

P. Montazer and W. E. Wilson, "Conceptual Hydrologic Model of Flow in the Unsaturated Zone, Yucca Mountain, Nevada," US Geologial Survey Water Resources Investigations report 84-4345 (1984).

L. Moreno, I. Neretinieks, and T. Erikson, "Analysis of Some Laboratory Tracer Runs in Natural Fissures," Water Resource Res. 21, 951-958 (1985).

I. Neretnieks, "Diffusion in the Rock Matrix: An Important Factor in Radionuclide Retardation?" J. Geophys. Res. 85, 4379-4397 (1980).

I. Neretnieks, T. Eriksen, and P. Tḧtinen, "Tracer Movement in a Single Fissure in Granitic Rock: Some Experimental Results and Their Interpretation," Water Resour. Res. 18, 849-858 (1982).

A. Pentland, "Fractal-Based Description of Natural Scenes," IEEE Trans. Pattern Anal. Mach. Intell. 6, $661-674(1984)$.

R. R. Peters, et al., "Fracture and Matrix Hydrologic Characteristics of Tuffaceous Materials from Yucca Mountain, Nye County, Nevada," Sandia National Laboratories report SAND84-1471 (December 1984). 


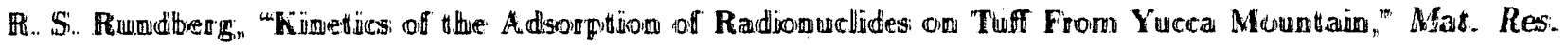

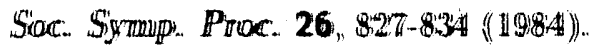

R. Rumdberg et all.," "Fractune Fllow Umulder Saturated Comditions;" Los Alamos National Laboratory report. (in pressi)).

Fit. B. Scrotti, R. W. Spengler, S. Diell A. R. Lappina, and M. Chormack, "Geologic Character of Tuffs in the

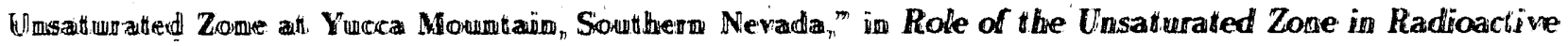
aumd Mazaundouss: Waste Dispocall (Amn Arbor Science Publishens, Amn Arbor, Michigan, 1983), p. 289-335.

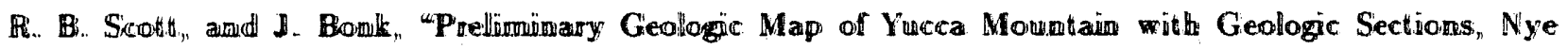
Conumby, Nevanda,"

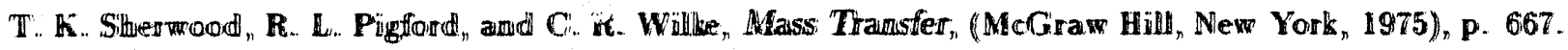

D.. B.. Simyde: $n$ amd W. 1. Carr, "Prelioninary" Resultss of Gravity Imvestigations at Yucca Mountain and Vurcimulty, Sonutherm Nye Corwmity, Nevadta," US Geological Survey open-fille report 82-701 (1982).

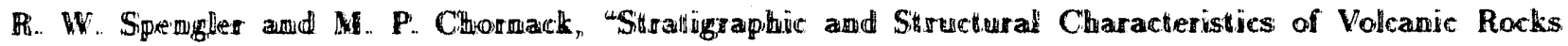
im Cone Holve USW G-4, Yucca Monumidim, Nye Coumbs; Nevada," US Geological Survey open file report USGS-OFR-84-780 (198.4)).

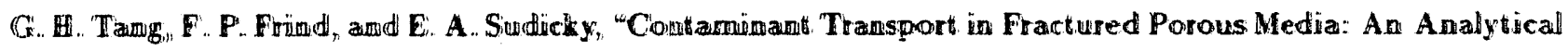

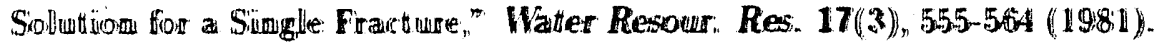

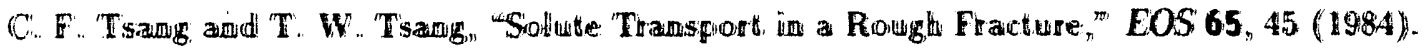

h. W. Thonvas, "A Sumumary Report" on Sorption Measurements Performed with Yucca Mountain Tuff Samplyes amd Water From Well J-13, Los Alamos: National Laboratory report LA-10960-MS (December 19867).

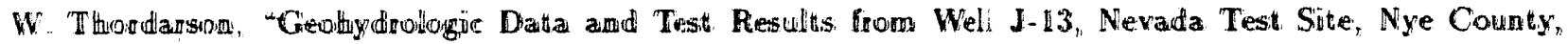
Nevarda, US Geological Surney Water Resources: Envestigations report 83-4171 (1983)).

B.. A. Trawis et. all., "Prellimminary Estumatte: of Water Flow and Radionuclide Transport in Yucca Mountain," Los Allamo National Laboratory elocumer: LA-UR-8440: (Jamuary 1984).

Di. Vamirnam et all., "Vartations in Authigenic Mineralogy and Sorptive Zeolite Abundance in Yucea Mountain, Nevarda, Based on Studies of Drill Cones USW-GV-3 and G-3," Los Alamos National Laboratory report LAMT(10-MS (Jume $19 \times 44)$.

G. R. Walted and R. E. Kidd, "Management Techniques: for the Control of Salt Water Encroachment in Crastall Aquiters," Alabiama Waver Resource Restearch Center Project report B-073-ALA (1979)).

1. 1. Wimnograd and W. "Thordinson, "Hydrogeolongie and Hydrochemical Framework, South Centrall Great. Biasim, Nevadia-Calitionmia, with Special Reference to the Nevadia Test Site," US Geological Survey Professional praperas $712-G(1975))$ 
P. A. Witherspoon, J. Y. Wang, K. Iwai, and J. E. Gale, "Validity of Cubic Law for Fluid Flow in a Deformable Rock Fracture," Lawrence Berkeley Laboratory report LBL-9557 (October 1979). 


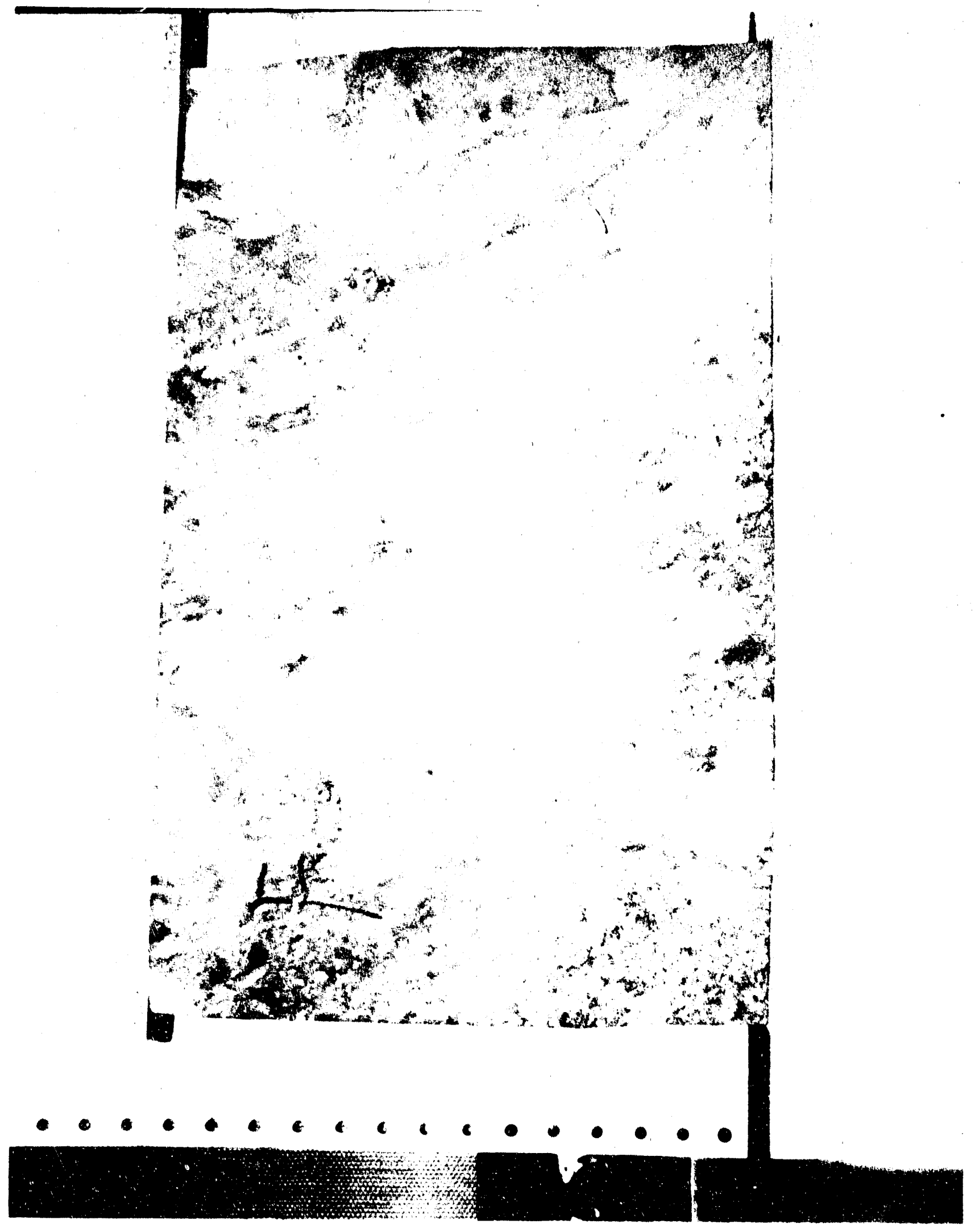

Fig. 1. Photo of a block face. 


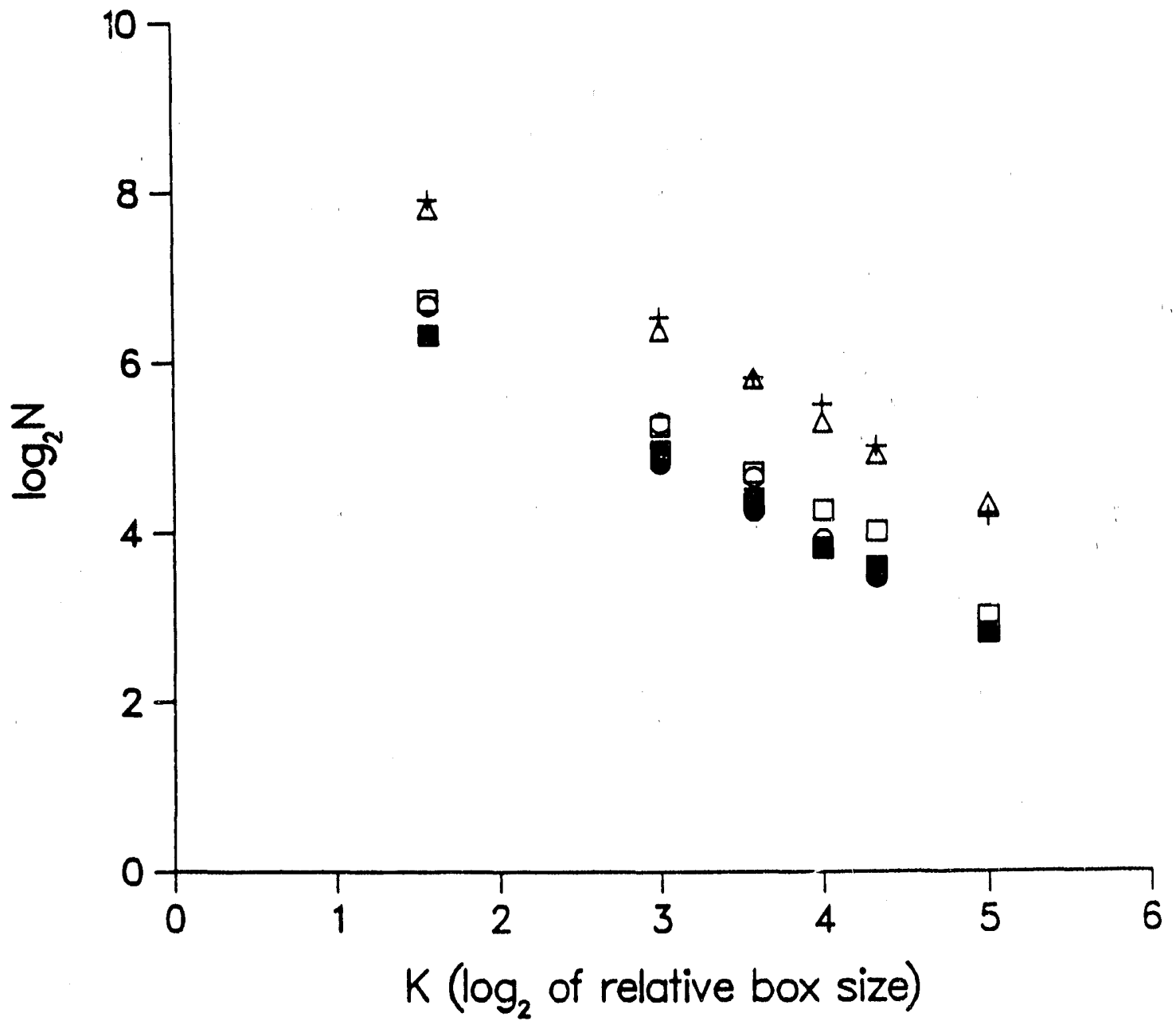

Fig. 2. Fractal box dimension analysis of fracture network. 


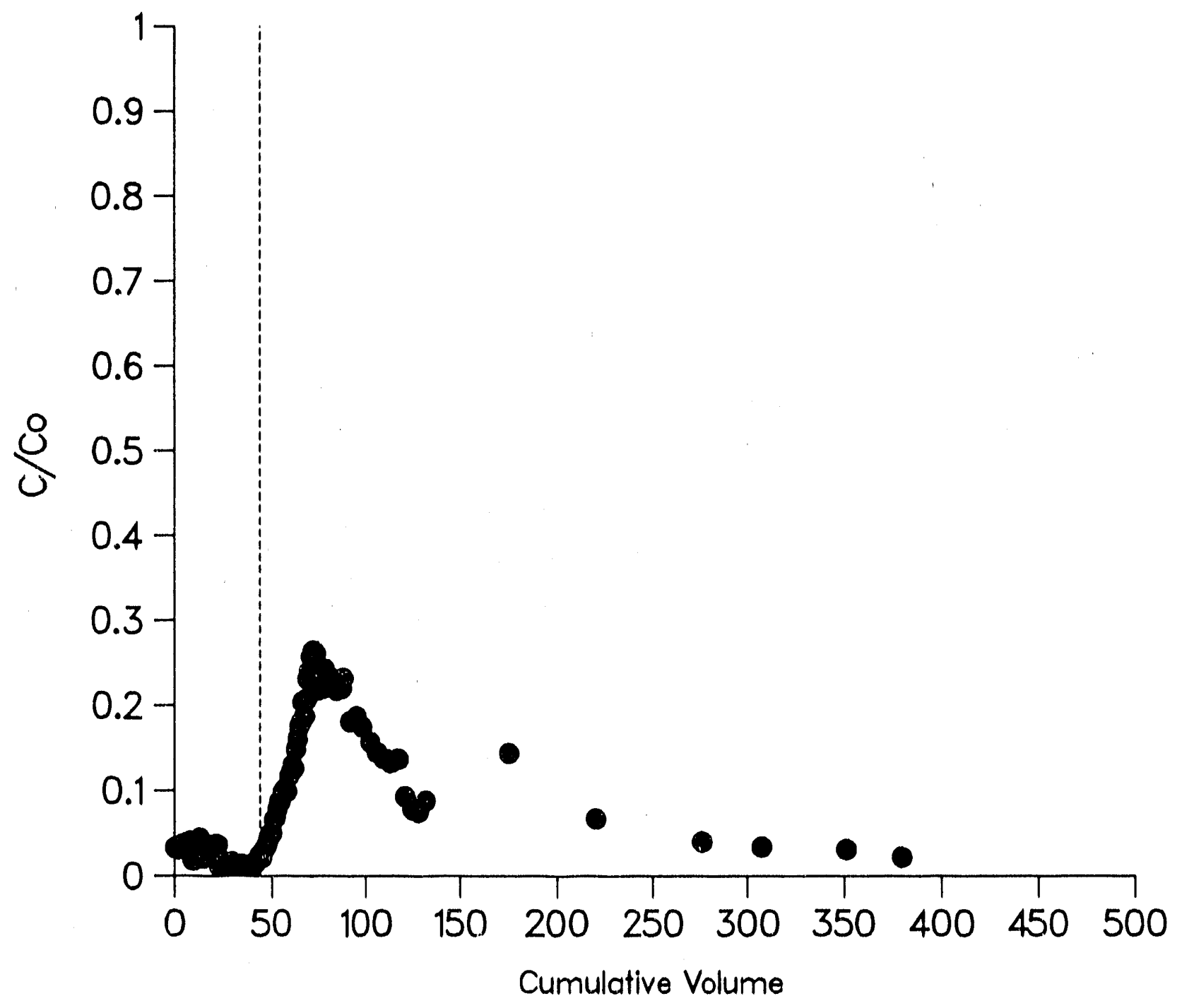

Fig. 3. First run of IITO-spiked J-13 water in Topopah Spring Member fracture network column at a flow rate of $0.91 \mathrm{~m} \ell / \mathrm{hr}$; initial H'TO concentration was $511.55 \mathrm{cpm} / \mathrm{m} \ell$. After $43.9 \mathrm{~m} \ell$ of eluent was collected, the input solution was changed to pure $\mathrm{J}-13$ water (dashed line). 


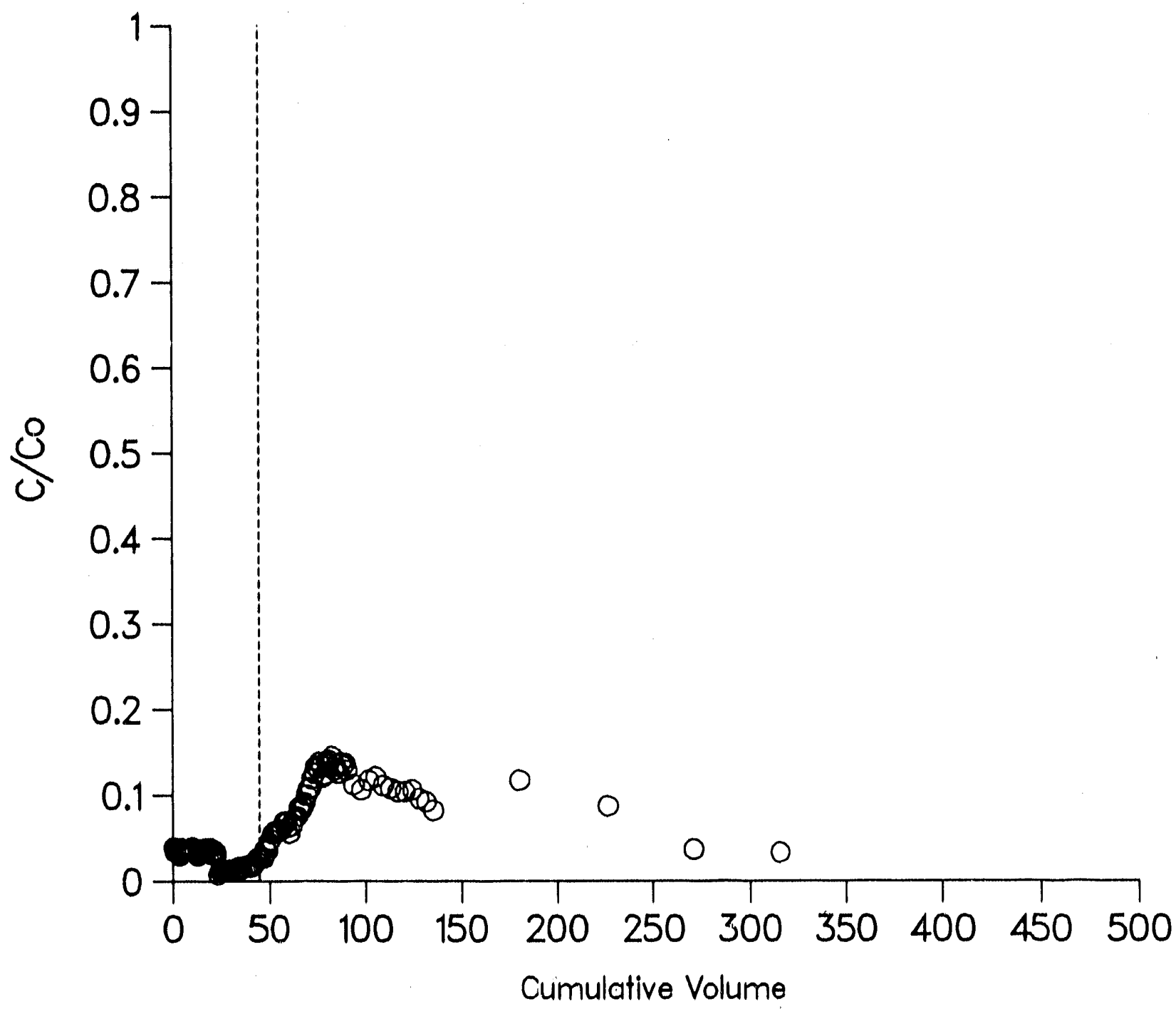

Fig. 4. Second run of HTO-spiked J-13 water in Topopah Spring Member fracture network column at a flow rate of $0.94 \mathrm{~m} \ell / \mathrm{hr}$; initial HTO concentration was $494.80 \mathrm{cpm} / \mathrm{m} \ell$. After $44.9 \mathrm{~m} \ell$ of eluent was collected, the input solution was changed to pure J-13 water (dashed line). 


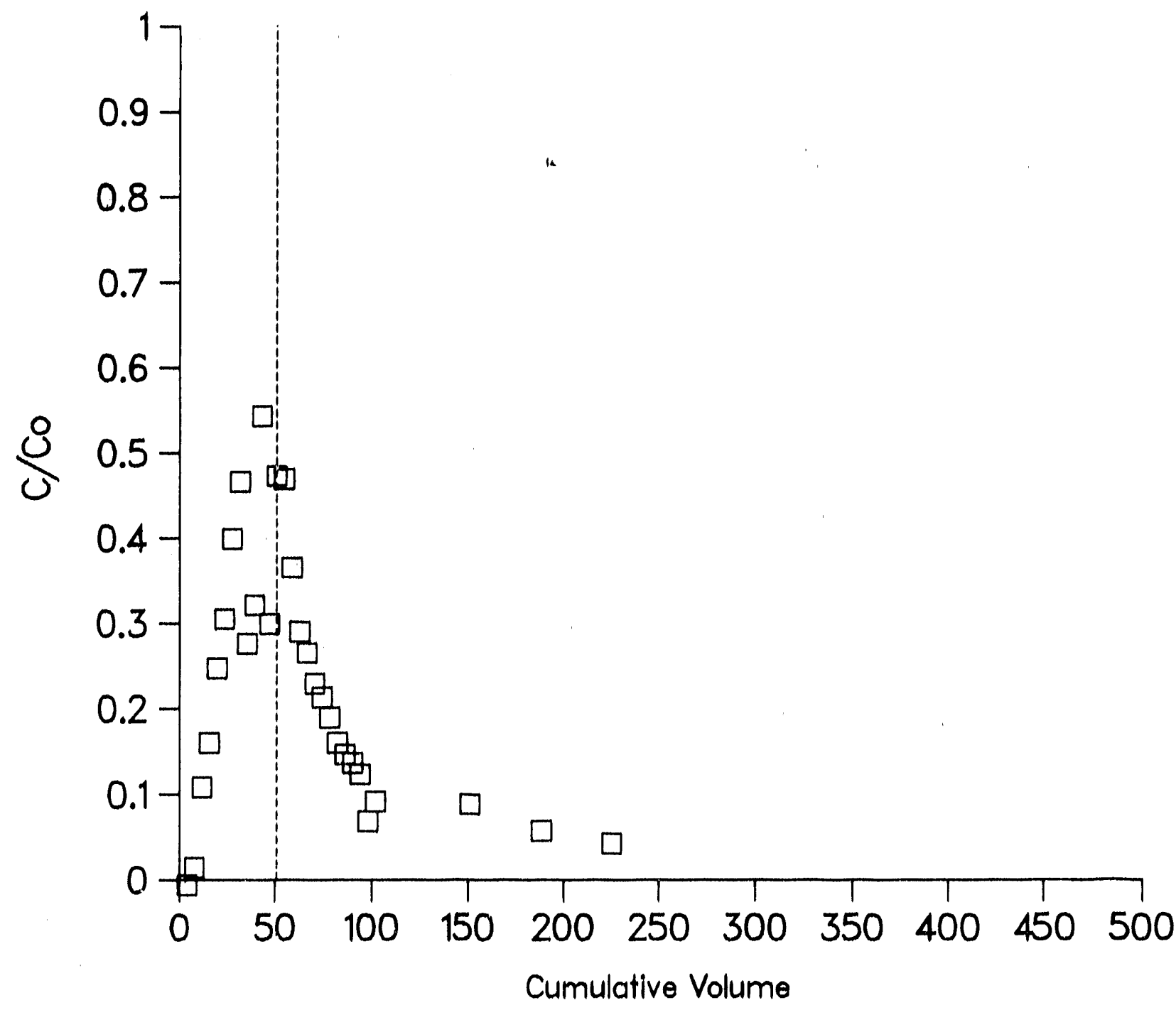

Fig. 5. Third run of H'TO-spiked J-13 water in Topopah Spring Member fracture network column at a flow rate of $0.98 \mathrm{ml} / \mathrm{hr}$; initial HTO concentration was $973.70 \mathrm{cpm} / \mathrm{m} \ell$. After $50.96 \mathrm{~m} \ell$ of eluent was collected, the input solution was changed to pure J-13 water (dashed line). 


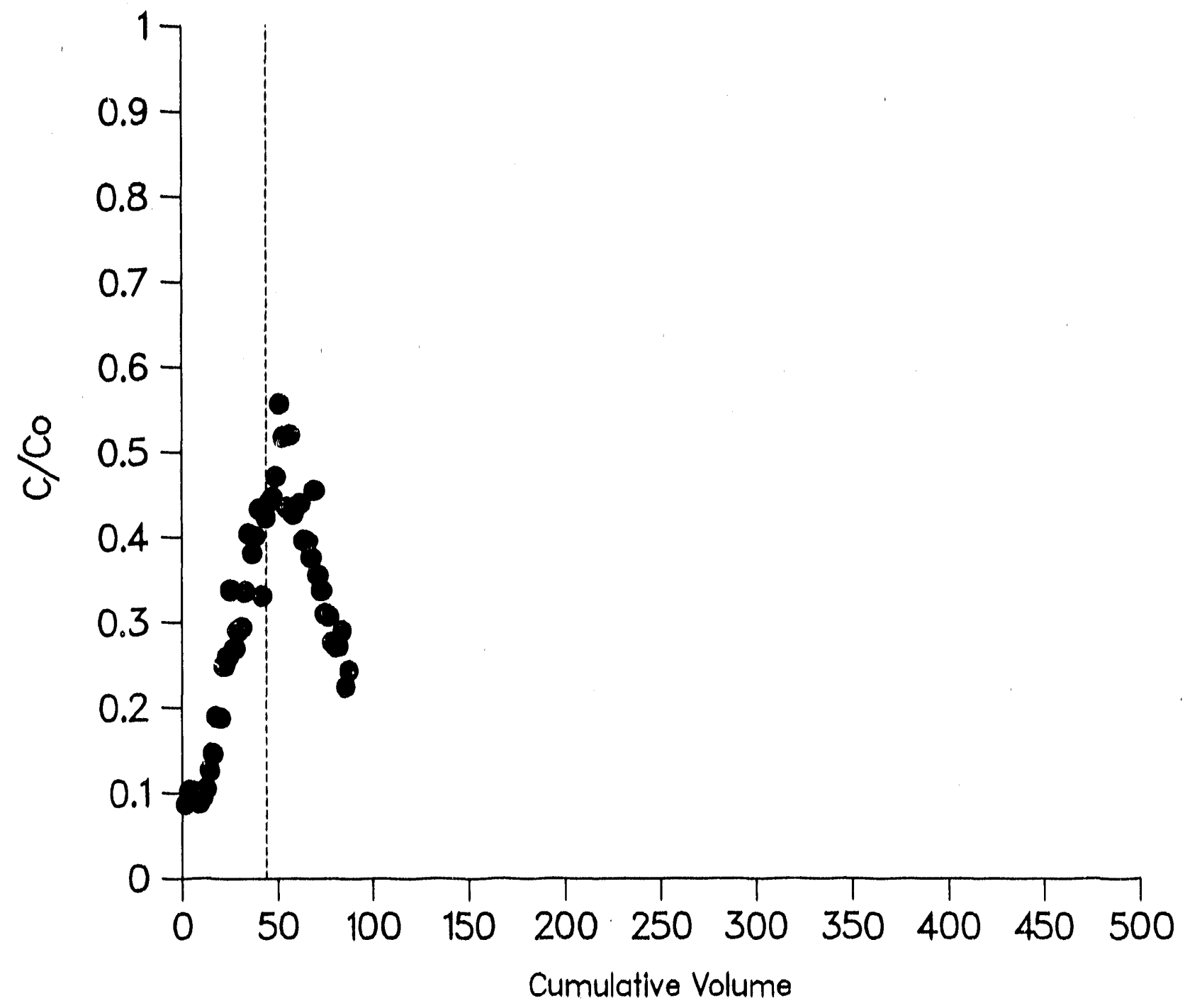

Fig. 6. First run of $\mathrm{TcO}_{4}^{-}$-spiked J-13 water in Topopah Spring Member fracture network column at a flow rate of $0.94 \mathrm{~m} \ell / \mathrm{hr}_{\text {; }}$ initial $\mathrm{TcO}_{4}^{-}$concentration was $3360 . \mathrm{cpm} / \mathrm{m} \ell$. After $45.1 \mathrm{~m} \ell$ of eluent was collected, the input solution was changed to pure J-13 water (dashed line). 


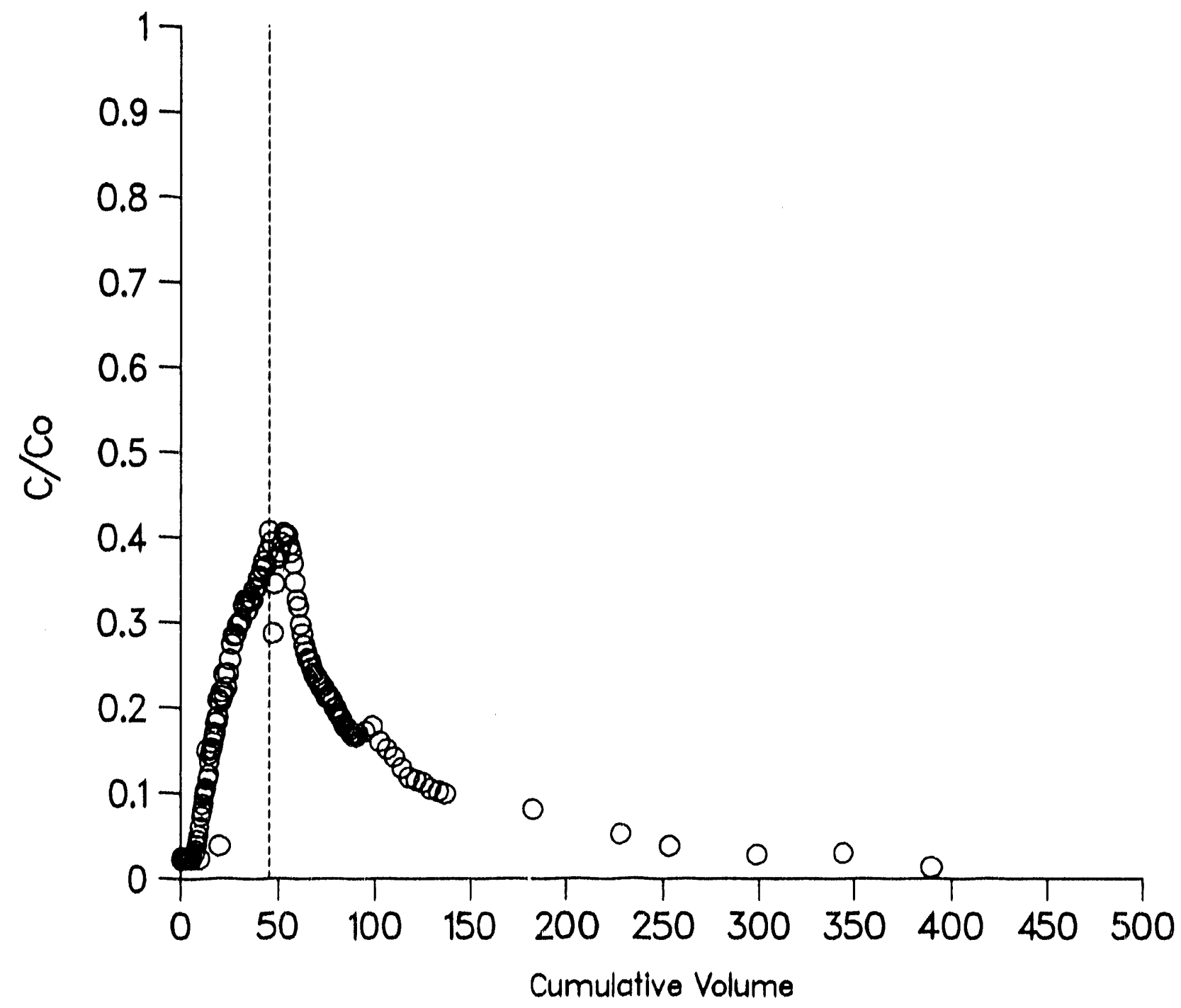

Fig. 7. Second run of $\mathrm{TcO}_{4}^{-}$-spiked J-13 water in Topopah Spring Member fracture network column at a flow rate of $0.95 \mathrm{~m} \ell / \mathrm{hr}$; initial $\mathrm{TcO}_{4}^{-}$concentration was $2616, \mathrm{cpm} / \mathrm{m} \ell$. After $45.5 \mathrm{~m} \ell$ of eluent was collected, the input solution was changed to pure J-13 water (dashed line), 


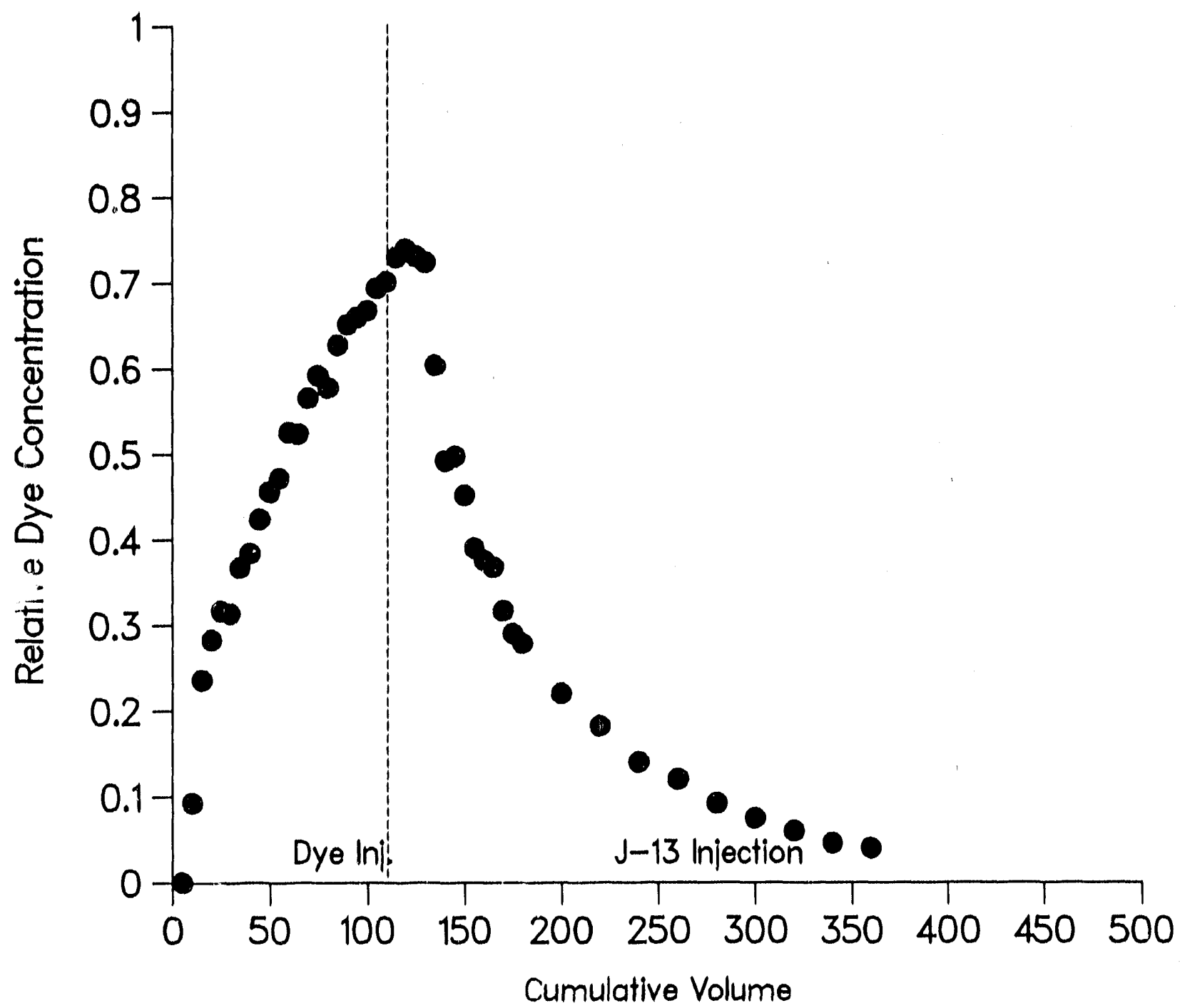

Fig. 8. Run of sulforhodamine B dye-spiked J-13 water in Topopah Spring Member fracture network column at a flow rate of $54.3 \mathrm{~m} \ell / \mathrm{hr}$. After $110.4 \mathrm{~m} \ell$ of eluent was collected, the input solution was changed to pure $\mathrm{J}-13$ water (dashed line). 


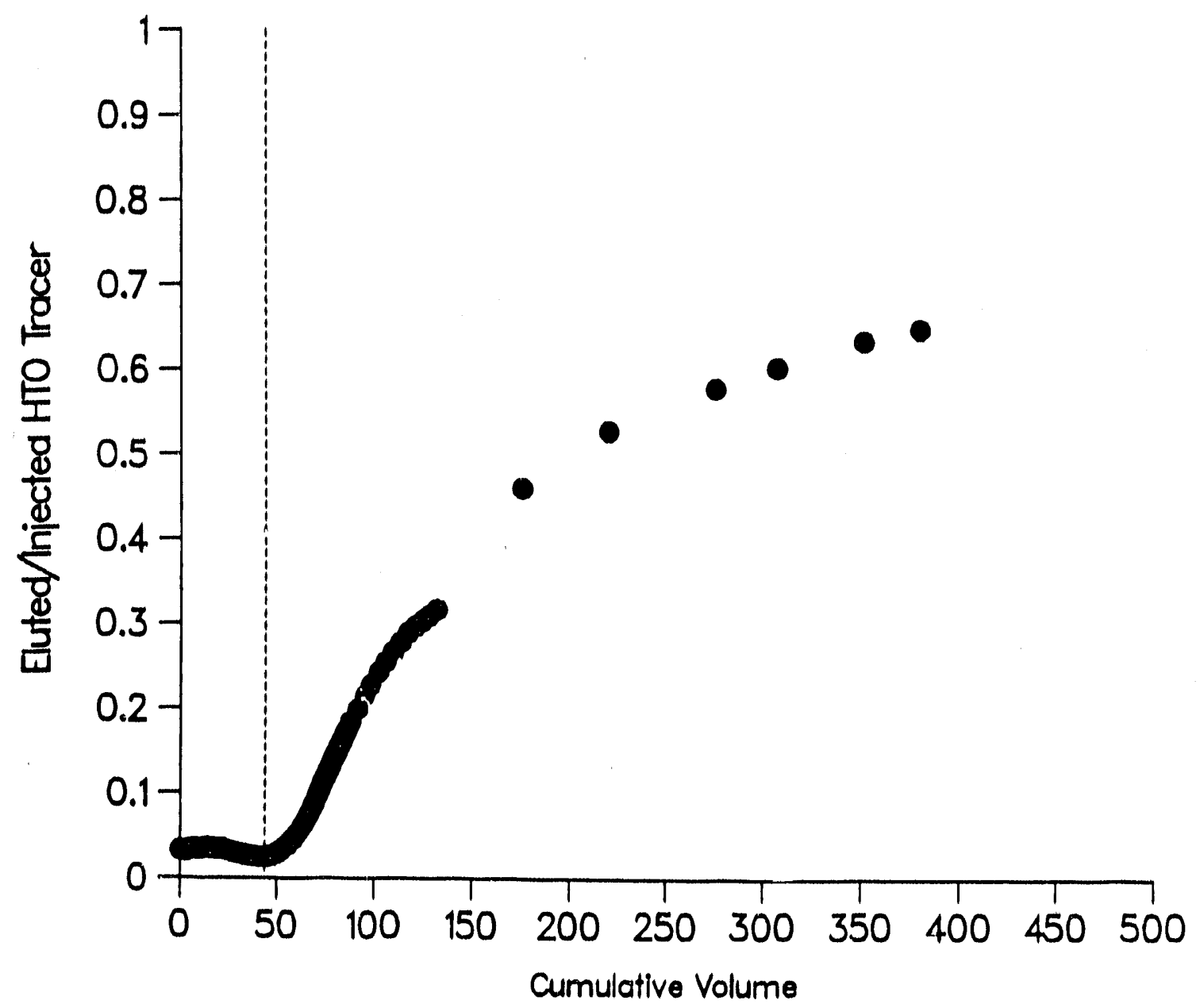

Fig. 0. Calculated sum of eluted tracer rolative to sum of injected tracer for flrst run of HTO-spikod J-13 water in 'Topopah Spring Member fracture network column. Data shown in Fig. 3. Dashed line indicates change to unspiked J-13 waler. 


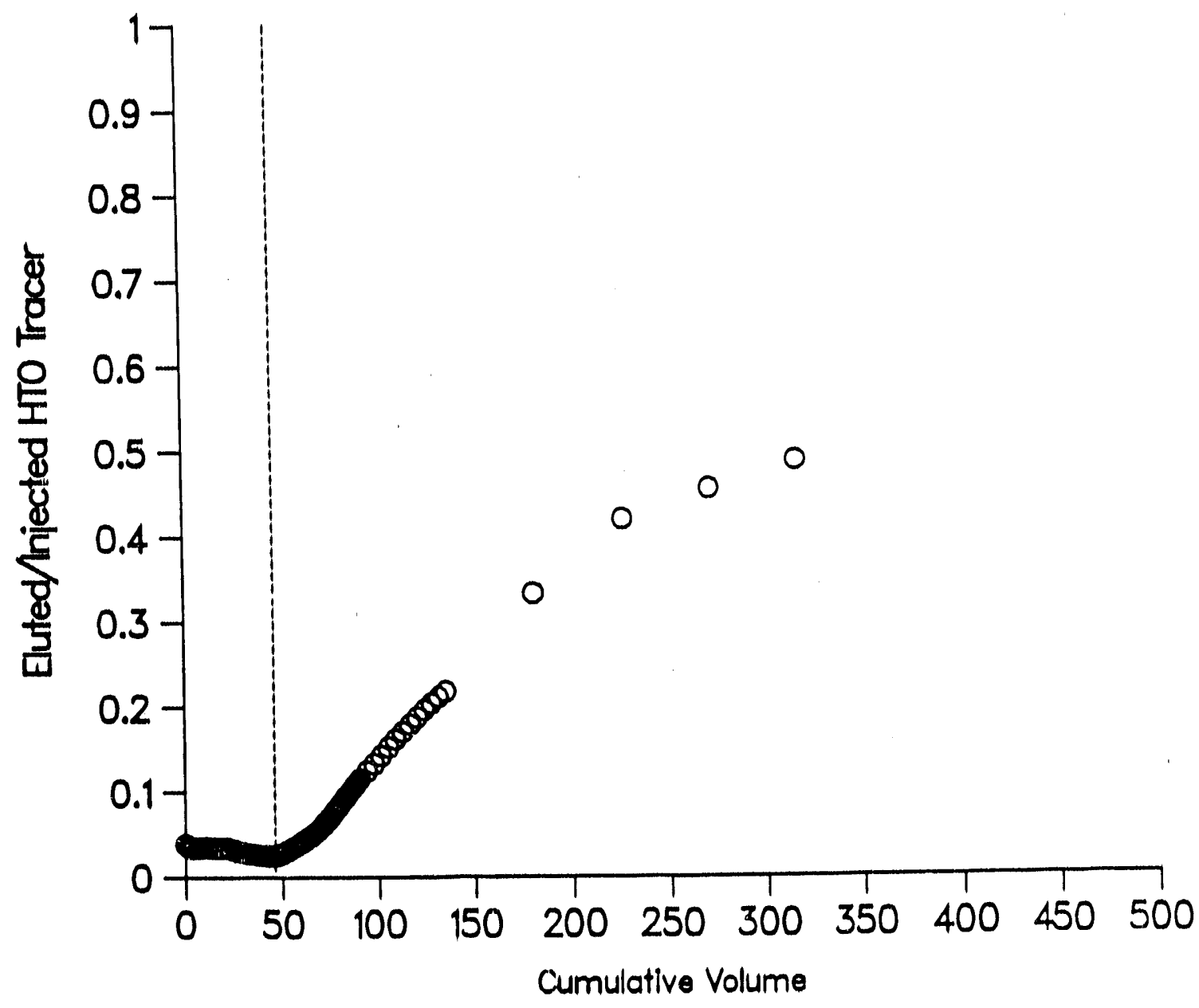

Fig. 10. Calculated sum of eluted tracer relative to sum of injected tracer for second run of IITO-spiked J-13 water in Topopah Spring Member fracture network column. Data shown in Fig. 4. Dashod line indicates change to unspiked J-13 water. 


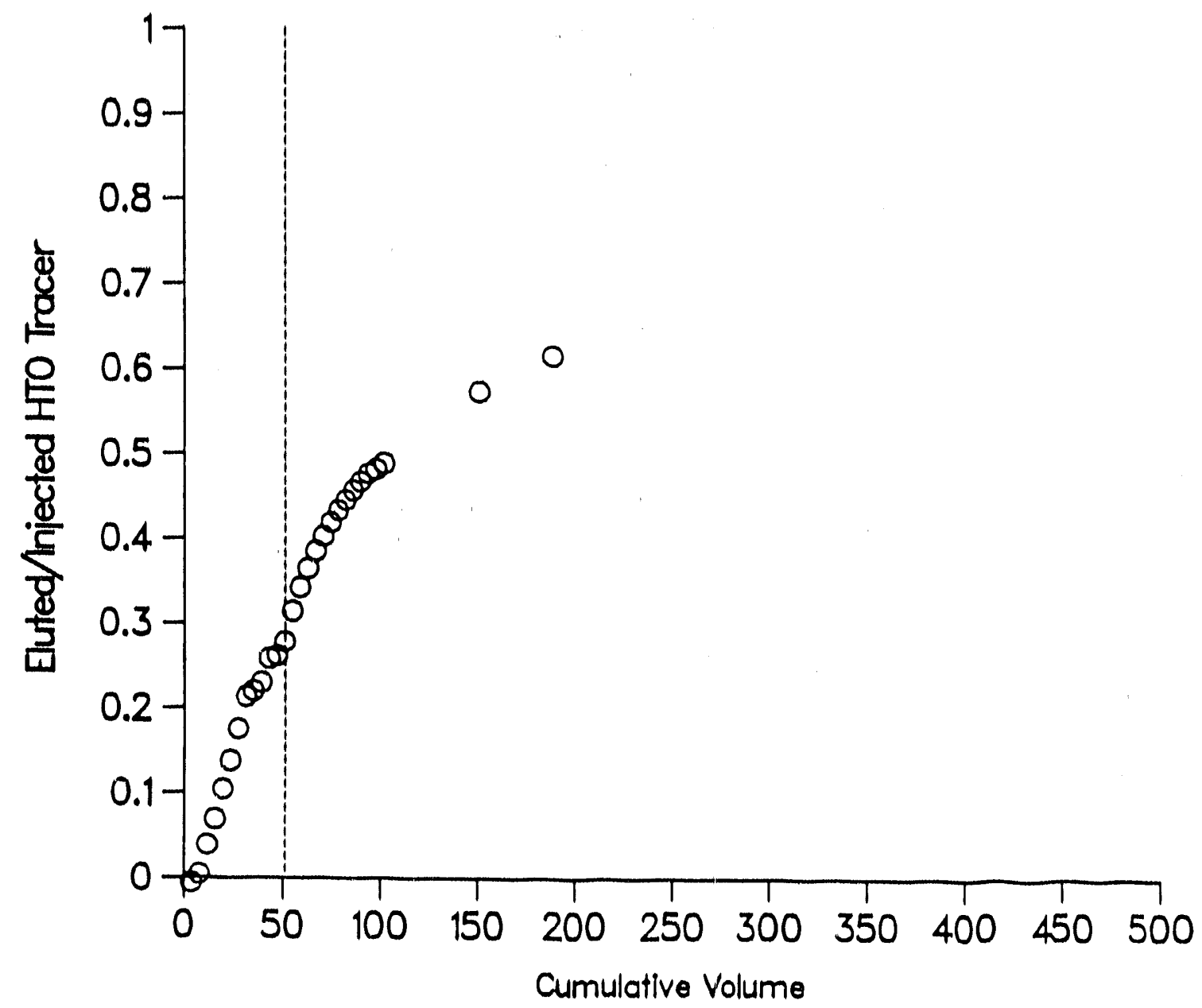

Prig. 11. Calculatod sum of eluted tracor relative to sum of injected tracer for second run of H'TO-spiked J-13 wator in Topopah Spring Member fracture network column. Data shown in Fig. 5. Dashed line indicates change to unspiked J-13 water. 


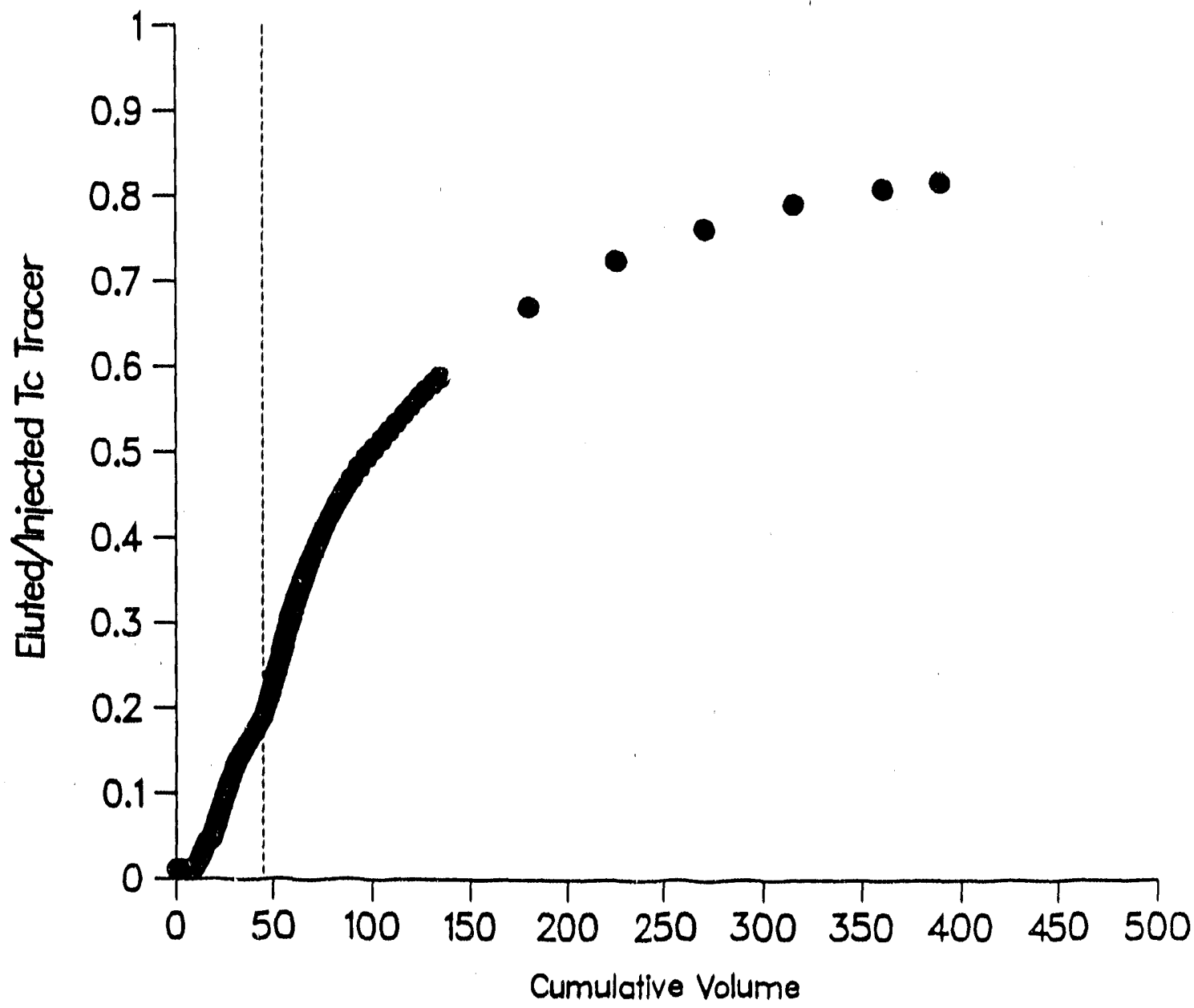

Fig. 12. Calculated sum of eluted tracer relative to sum of injected tracer for first run of pertechnetate-spiked J-13 water in Topopah Spring Member fracture network column. Data shown in Fig. 6. Dashed line indicates change to unspiked J-13 water. 


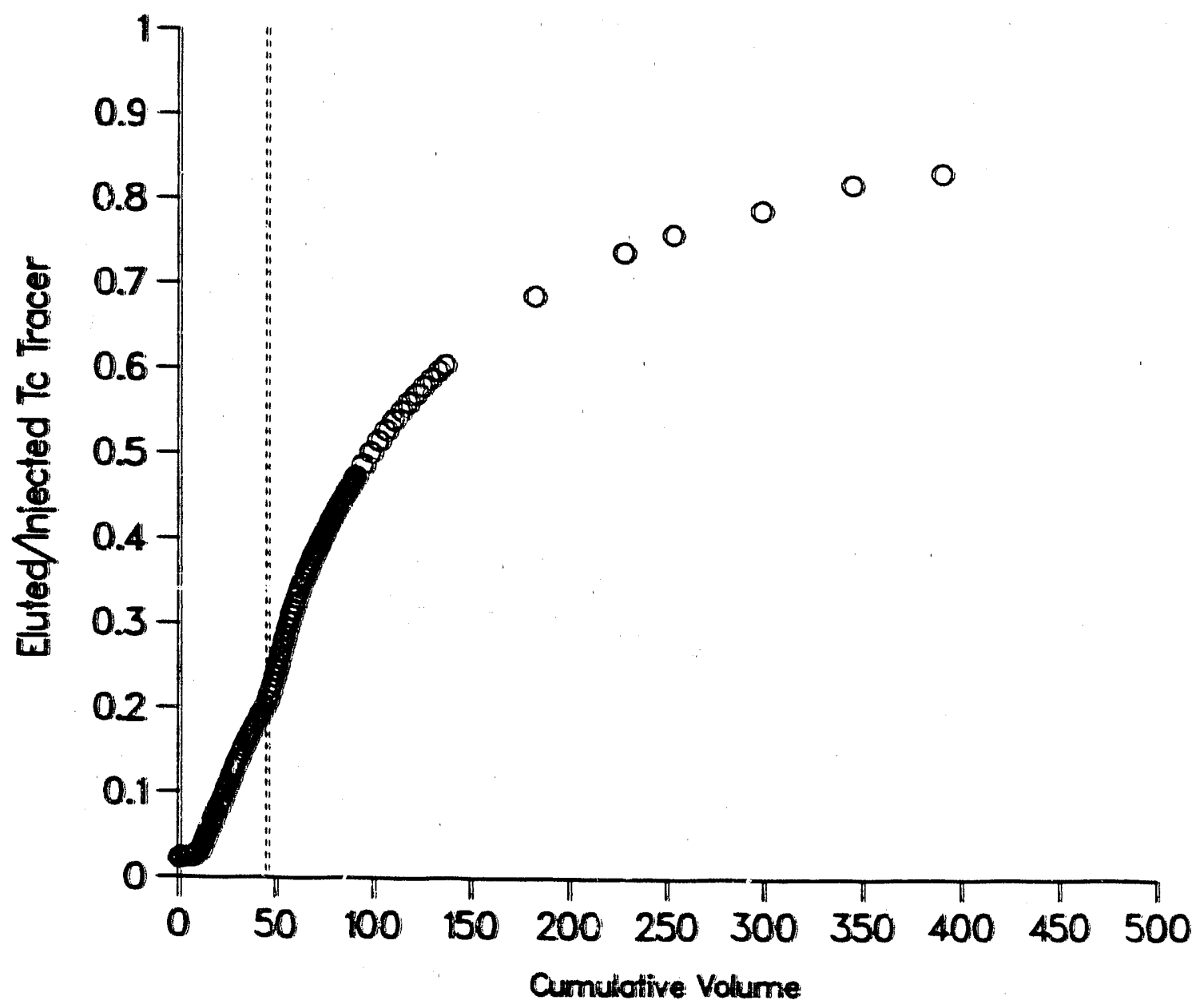

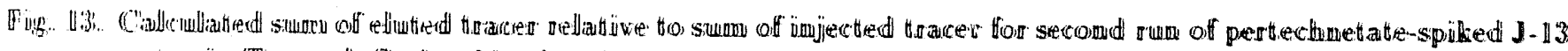

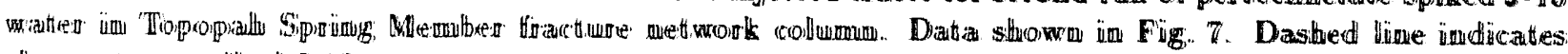

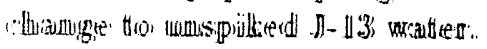




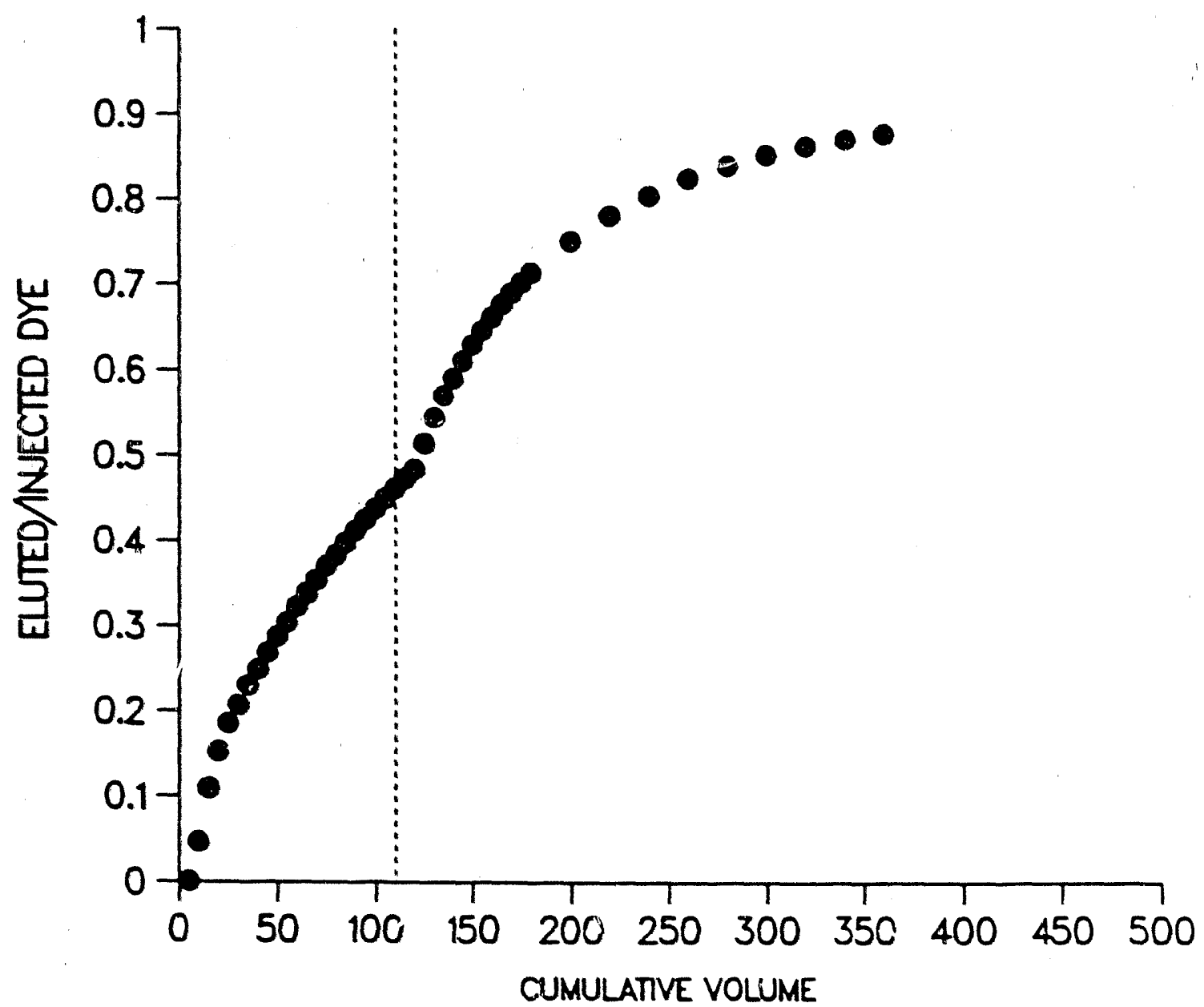

Fig. 14. Calculated sum of eiuted tracer relative to sum of injected tracer foi run of sulforhodamine B dye-spiked J-13 water in Topopah Spring Member fracture network column. Data shown in Fig. 8. Dashed line indicates change to unspiked $\mathrm{J}-1,3$ water. 


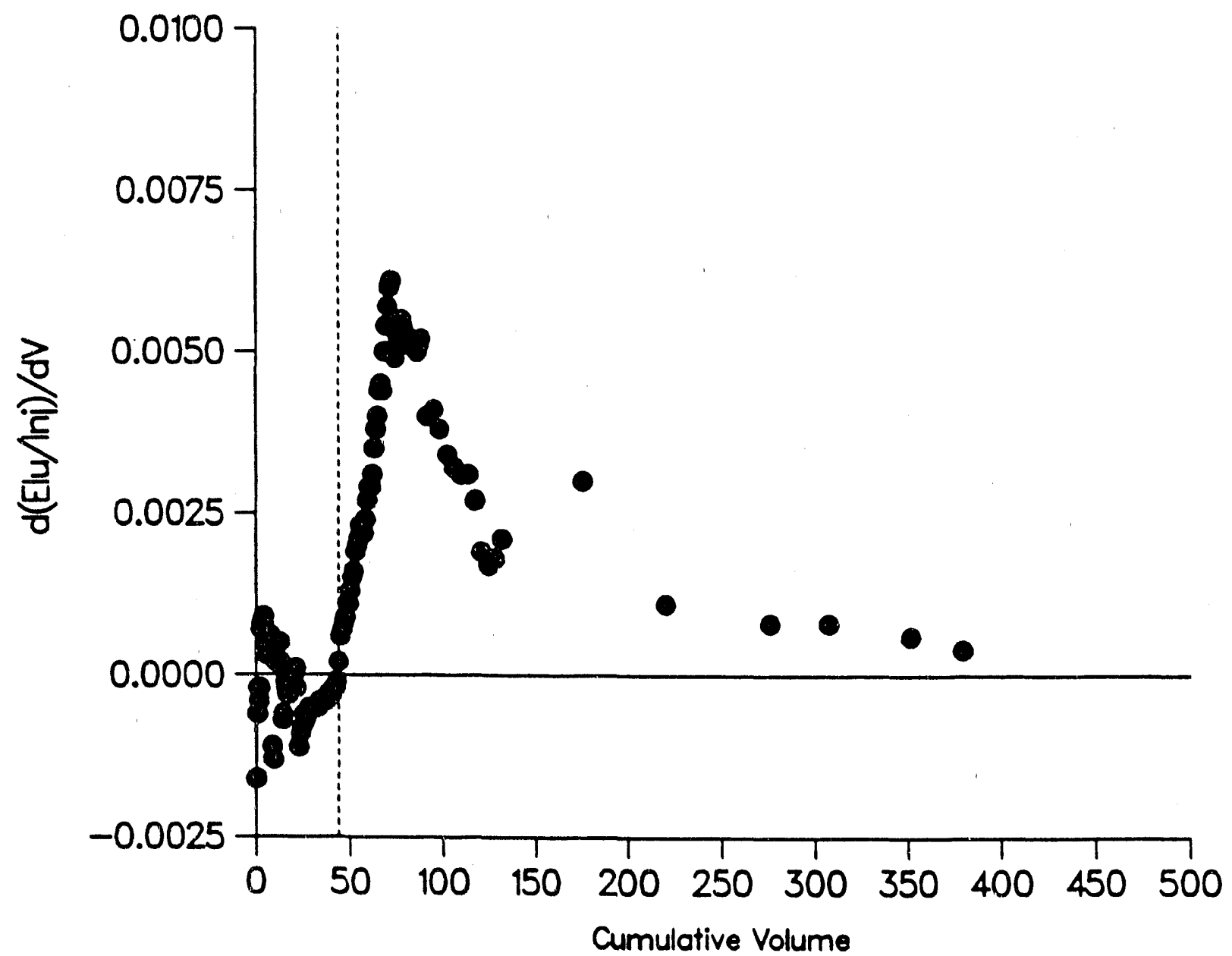

Fig. 15. Calculated rate of change for sum of relative eluted tracer from first run of HTO-spiked J-13 water in Topopah Spring Member fracture network column. Data shown in Fig. 9. Dashed line indicates change to unspiked J-13 water. 


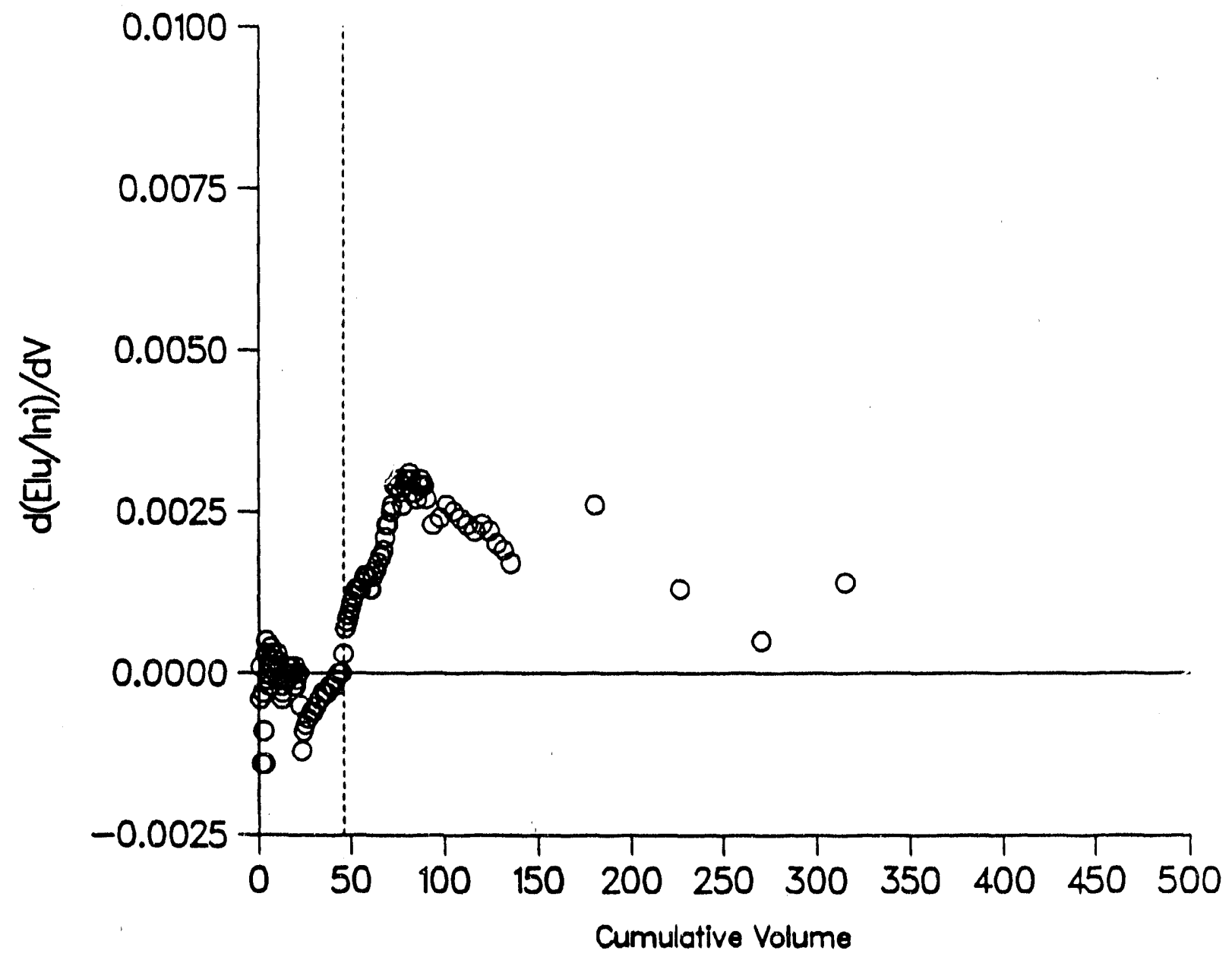

Fig. 16. Calculated rate of change for sum of relative eluted tracer from second run of IITO-spiked J-13 water in Topopah Spring Member fracture network column. Data shown in Fig. 10. Dashed line indicates change to unspiked J-13 water. 


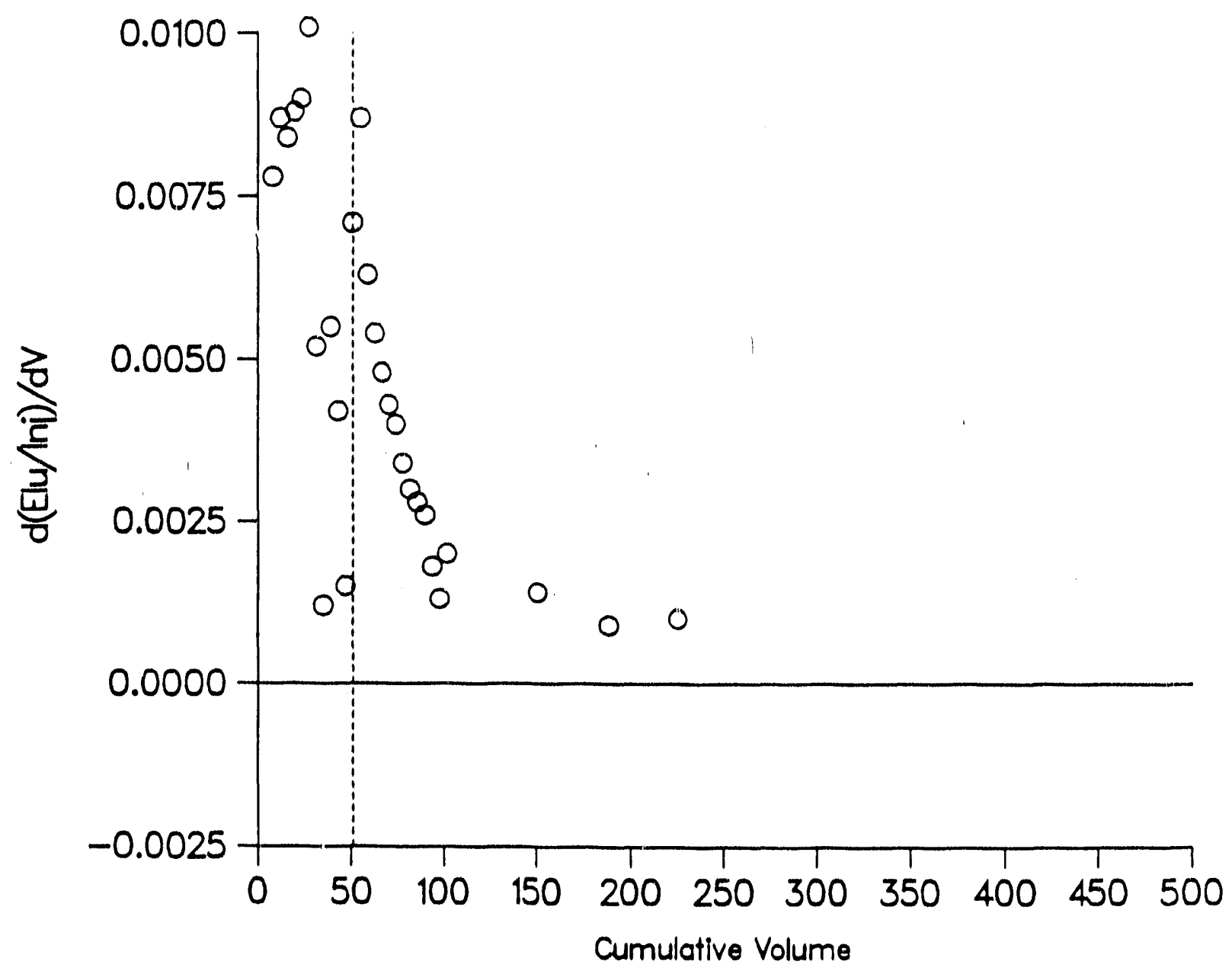

Fig. 17. Calculated rate of change for sum of relative eluted tracer from second run of HTO-spiked J-13 water in Topopah Spring Member fracture network column. Data shown in Fig. 11. Dashed line indicates change to unspiked J-13 water. 


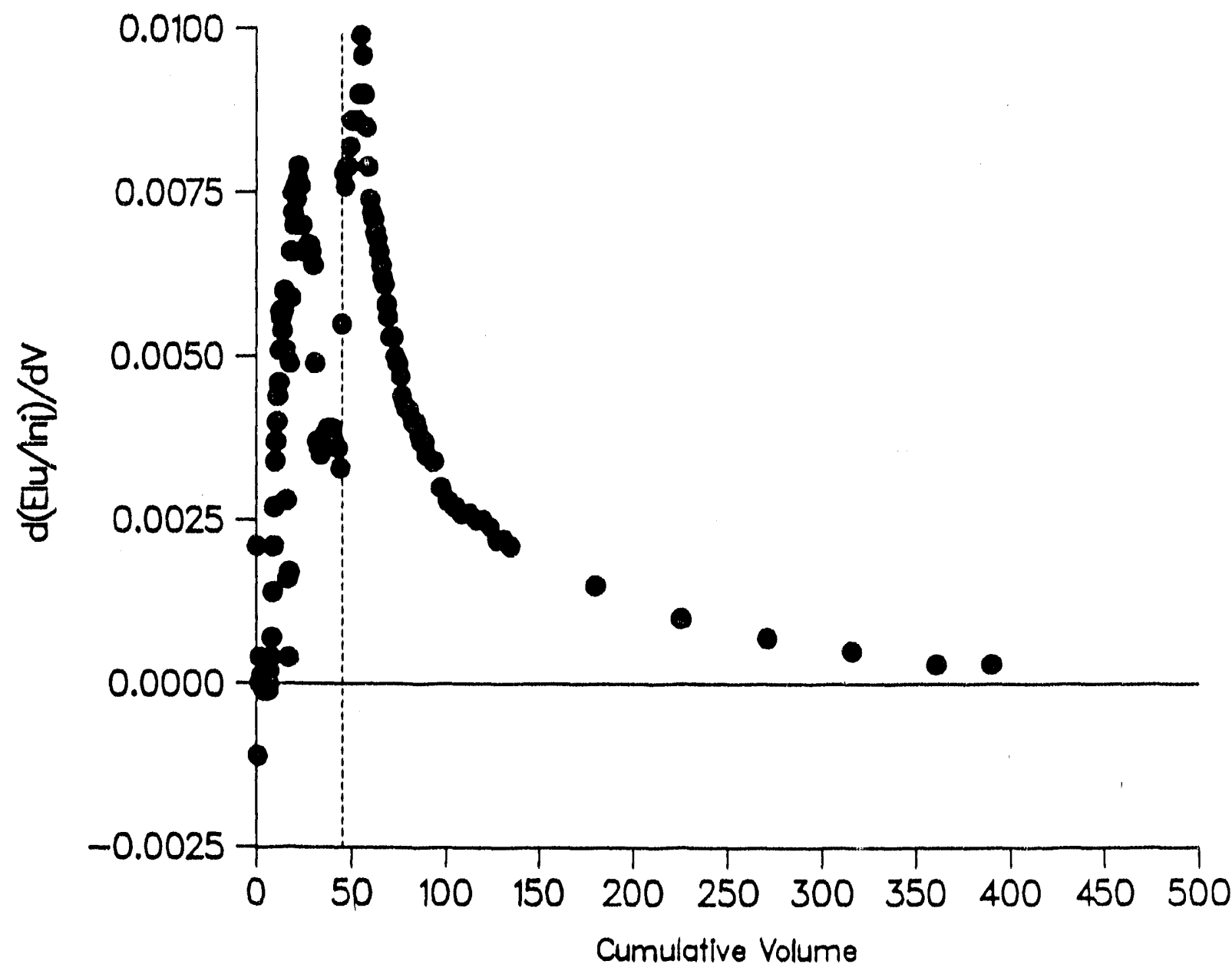

Fig. 18. Calculated rate of change for sum of relative eluted tracer from first run of pertechnetate-spiked J-13 water in Topopah Spring Member fracture network column. Data shown in Fig. 12. Dashed line indicates cliango to unspiked J-13 water. 


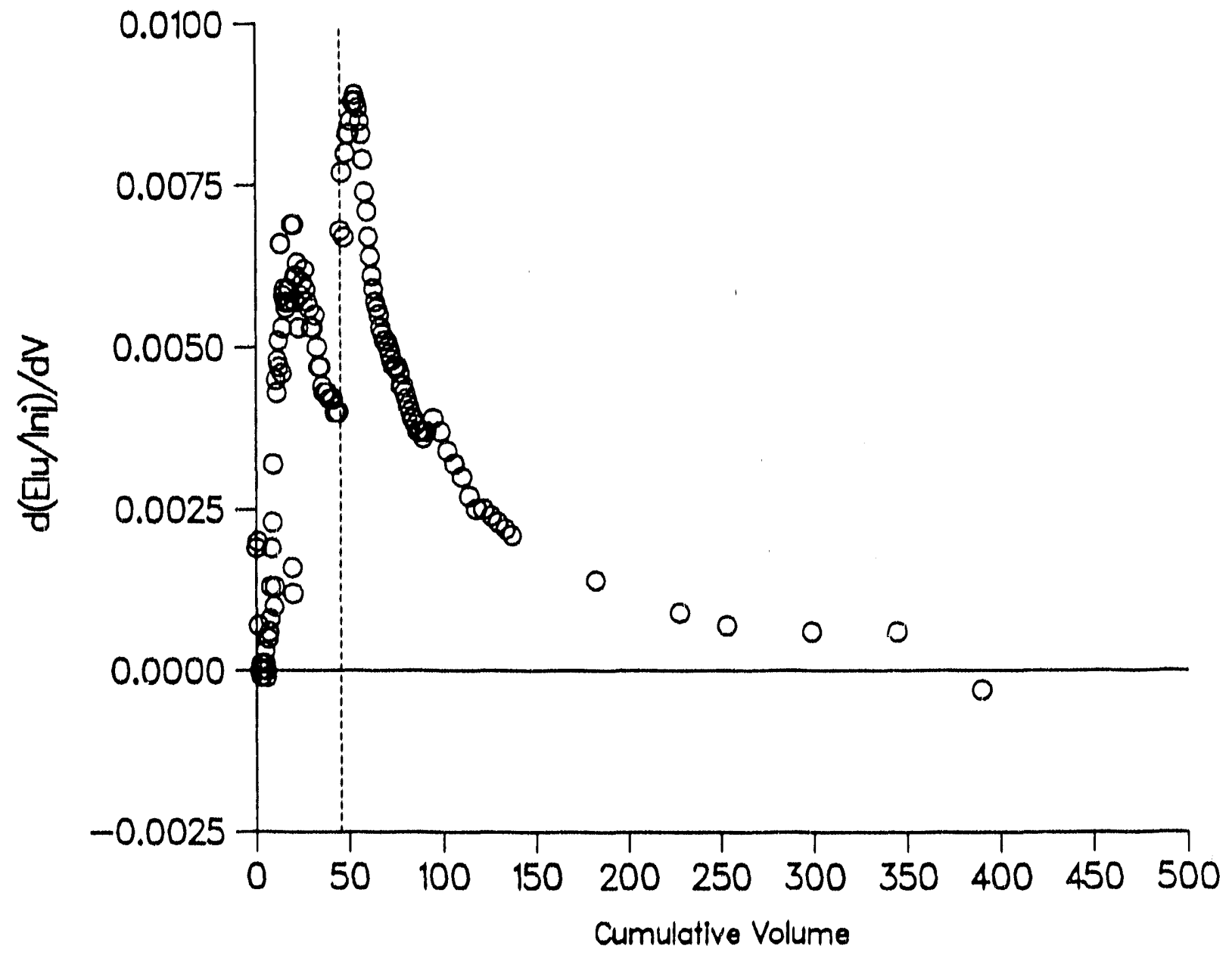

ligg. 19. (alculated rale of change for sum of relative eluted tracer from second run of pertechnotate-spiked J-13 water in 'Topopah Spring Member fracture network column. Data shown in Fig. 13. Dashed line indicates change to unspiked J-13 water. 


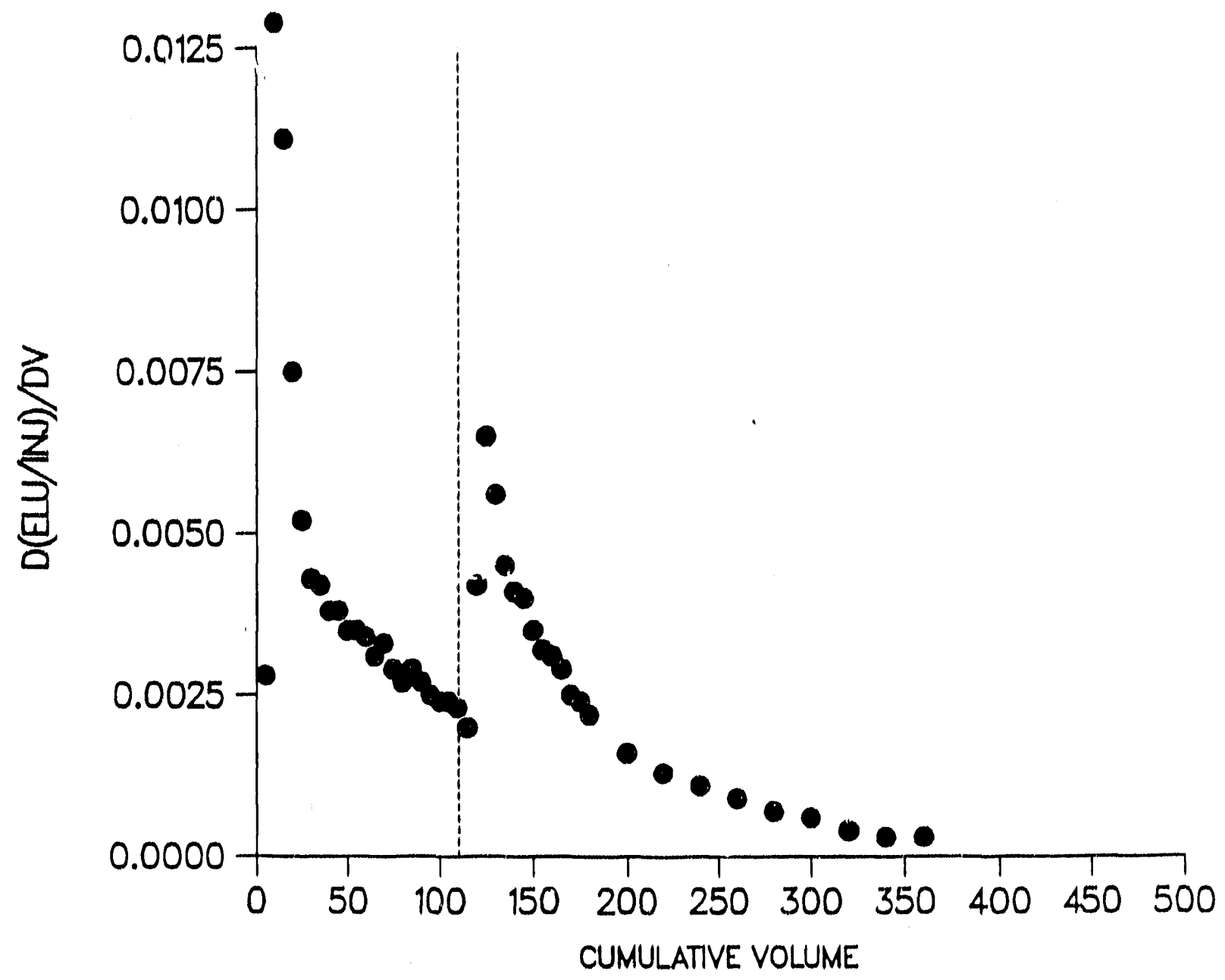

Fig. 20. Calculated rate of change for sum of relative eluted tracer from run of sulforhodinino B dye-spiked J-13 water in Topopah Spring Member fracture network column. Data shown in Fig. 14. Dashed line indicates change to unspiked J-13 waler. 


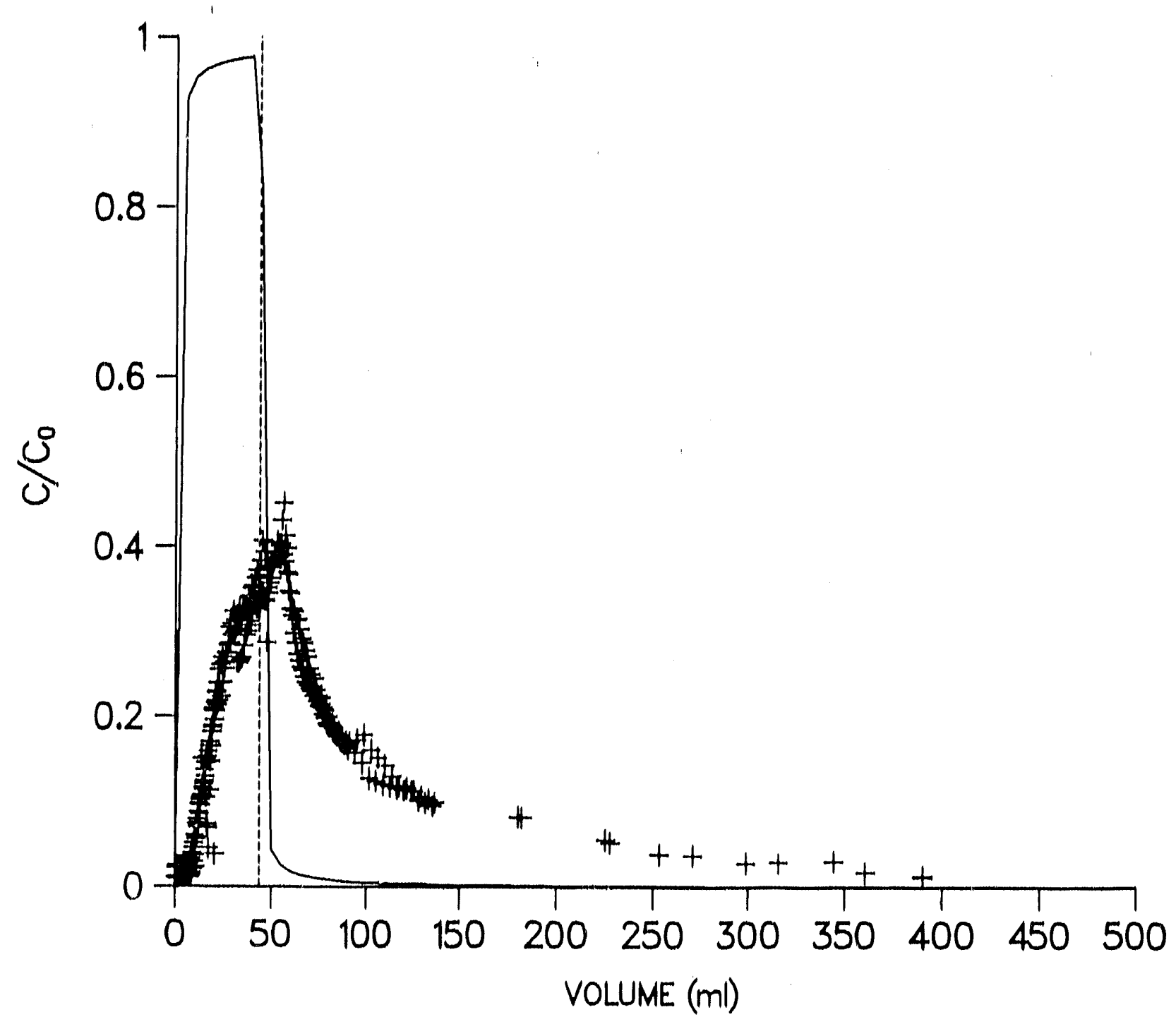

Fig. 21. Model for portechnebute tracer olution through a single parallel-sided fracture in a porous modium uses the paraneters for model 0 in 'lable II. Fracture aperture of $0.00692 \mathrm{~cm}$ was determined from hoad and flow rate measurement.s. Compare to experimental elution curves in Figs. 6 and 7. Dashed line indicates change to Inspiked J-13 water. 


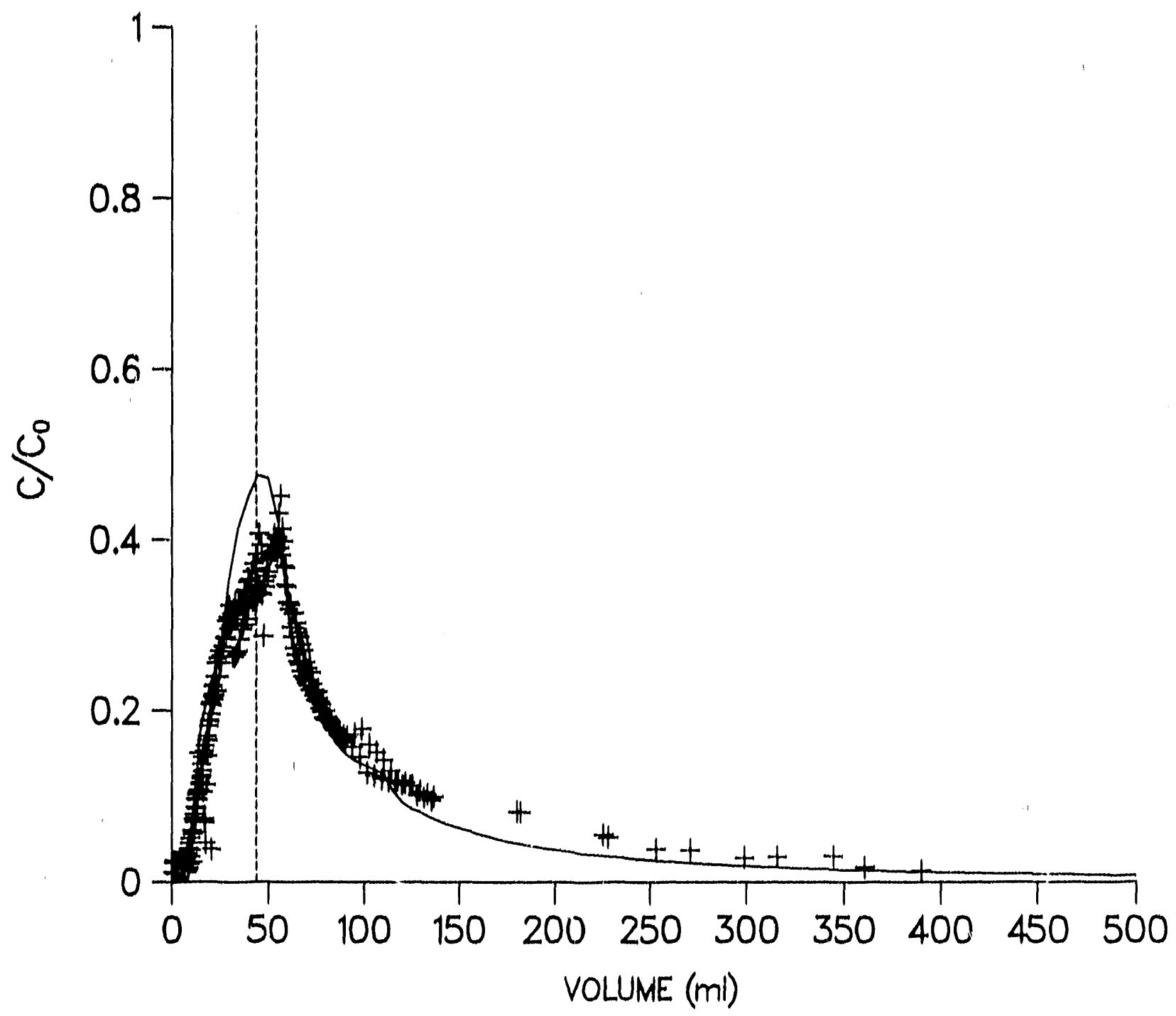

Fig. 22. Model for pertechnetato tracor olution through a singlo parallel-sided fracture in a porous medium uses the paraneters for model 1 in Table II. Fracturo aperture was sot to 0.1 cin to achiovo rotisonable flt to experimental data (Figs, 6 and 7); compare to Fig. 21. Dashed Ine Indicatos change to unsplked J-13 water. Irregularities in elution curvo shapes in theso modols are probably cansed by inaccurncies in liho numerical integration schemes used in the computer codo. (Information roceivod from R. Rundlherg, hos Alanos National Laborntory, 1087.) 


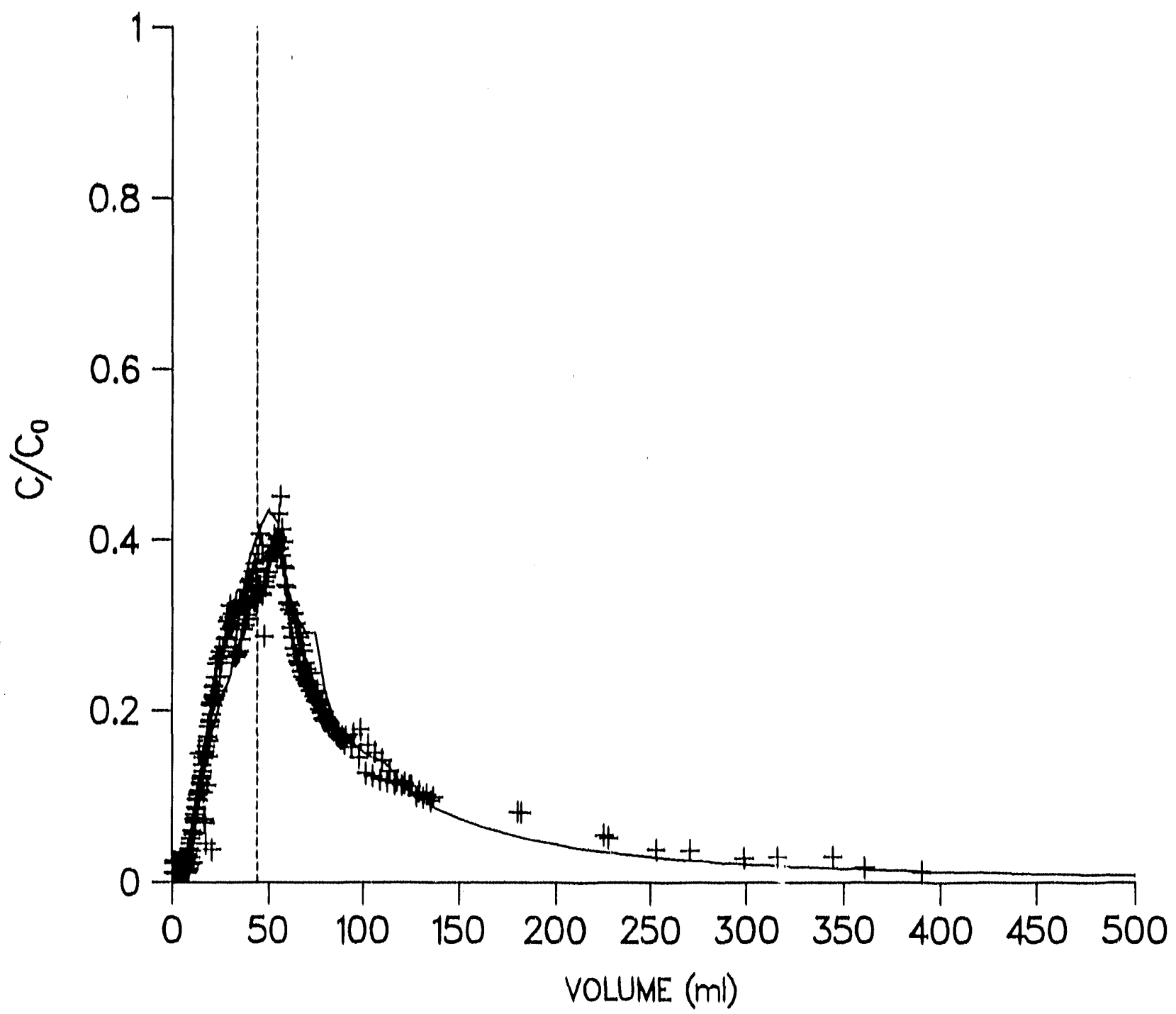

Fig. 23. Modol for pertechustate tracer olution through a singlo parallol-sided fracturo in a porous modium usos tho

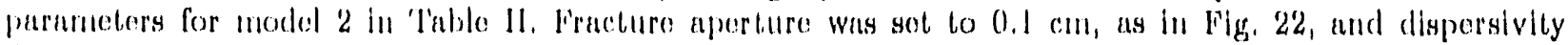

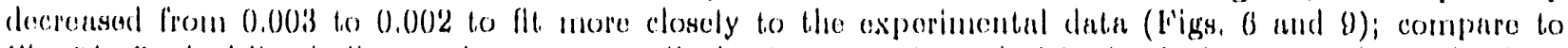
Fig. 21. Duslsed lino indicates shango to unspiked J-13 wator. Irrogularitios in olution curvo shapes in these models are probnhly cansed by inacenracios in the numorical integralion schome nsod in the computer code, (Intormation rocoived from R. Riundherg, Los Alanos National laboratory, 1087.) 


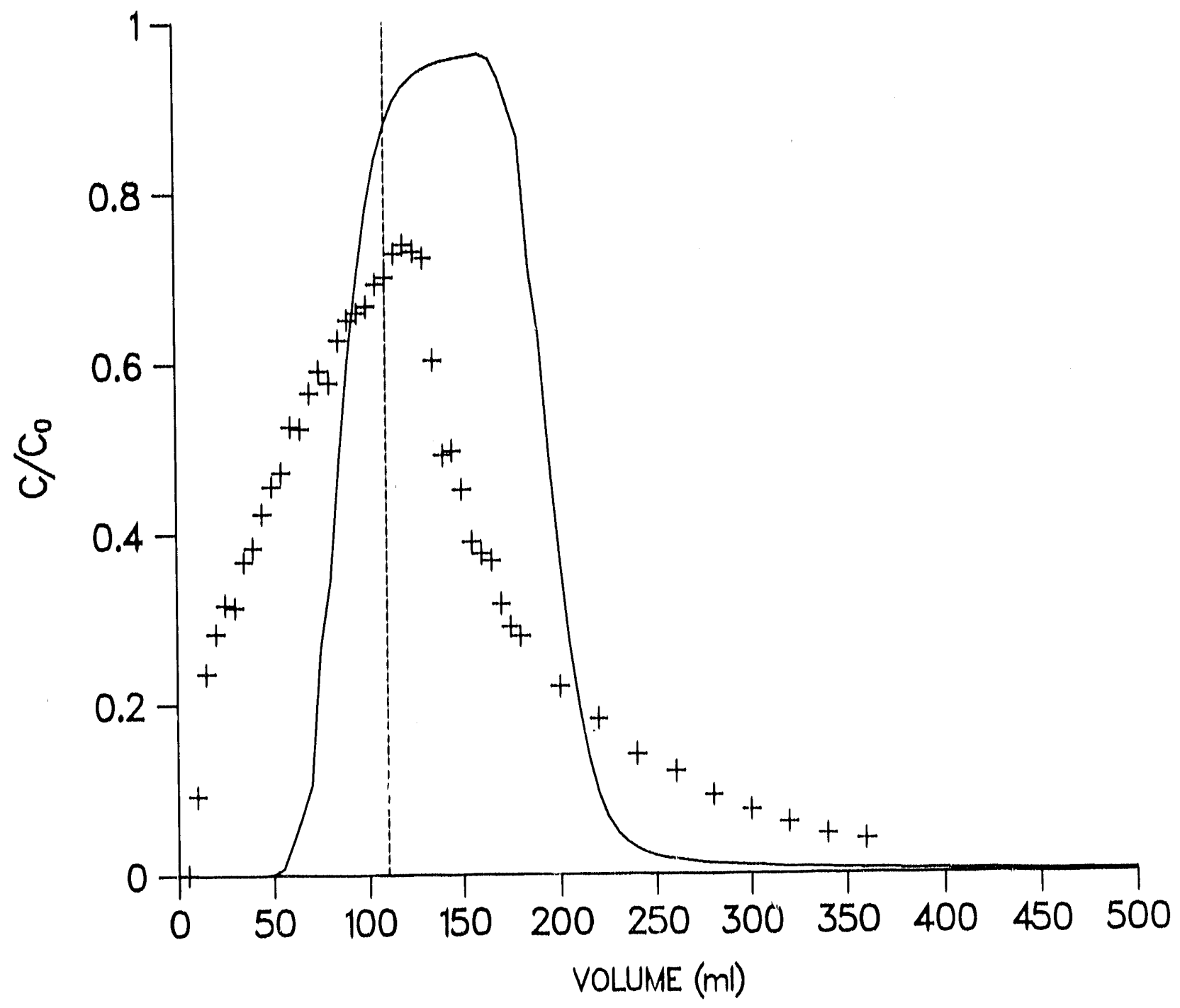

Fig. 24. Model for sulforhodamine B dye tracer elution through a single parallol-sided fracture in a porous medium uses the parameters for modol 3 in 'I'ablo II. Rock and fracture paranaters are identical to those used in Fig. 23. Flow rate and tracer injection volume wore changed to match experimo.. bal conditions (Table I and Fig. 8). Dashed line indicates change to unspik('d J-13 water. Irregularities in elution curve shapos in these models are probably caused by inaccuracies in the numorical intogration scheme used in tho computer code. (Information recolved from R. Rundborg, Los Alamos National Laboratory, 1987.) 


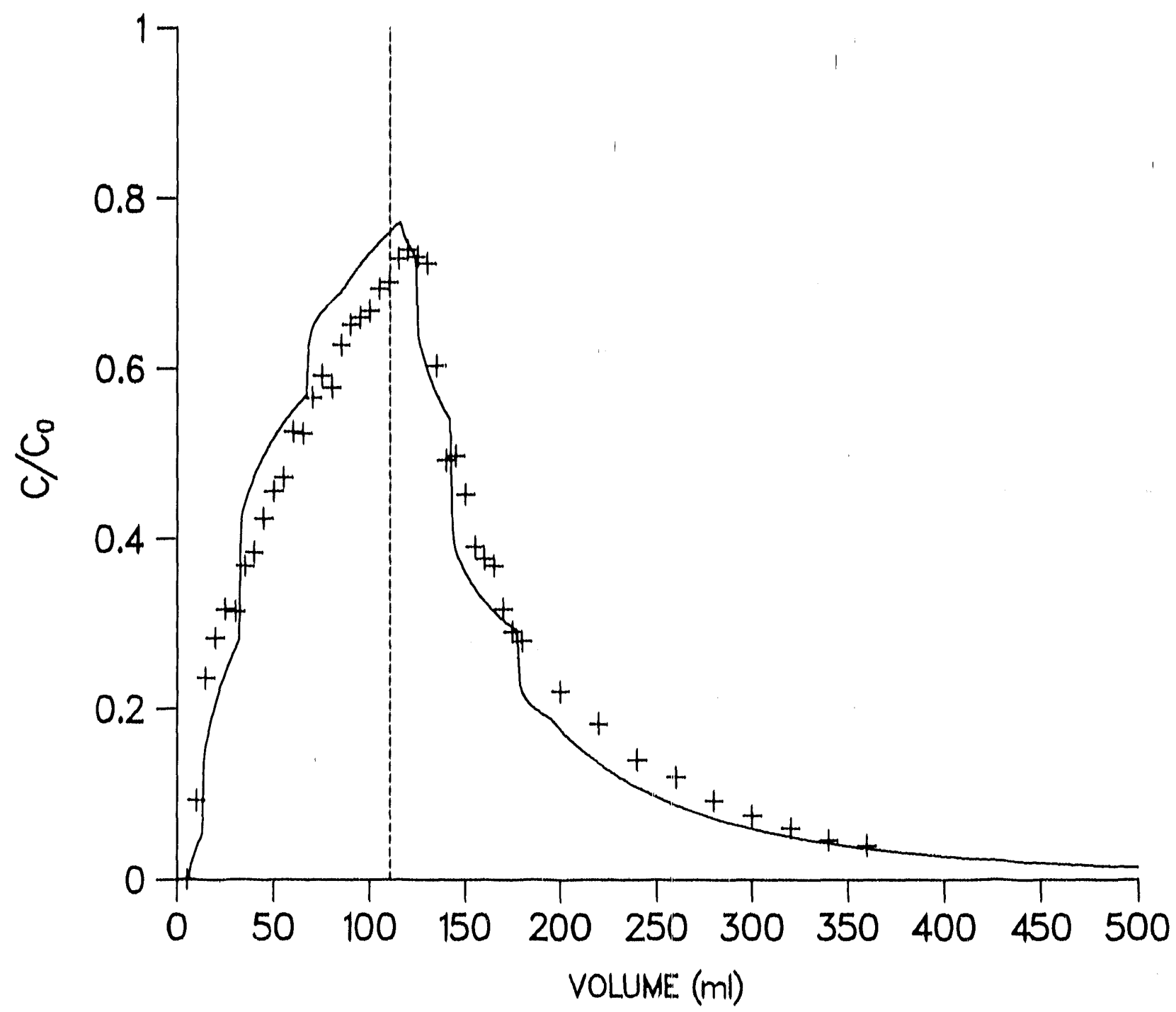

Fig. 25. Modol for sulforhodauno B dyo tracer olution through a singlo parallel-sided fracture in a porous medium uses the paraneters for model 4 in Tablo II. Model paraneters are identical to those used for Fig. 24 except that dispersivity was increased by a factor of 60 to compensate for increased flow rate; longitudinal dispersivity ('I'ang, 1981) is constant. Dashod lino indicates change to unspiked J-13 water. Irrogularities in elution curve shapes in these models are probably caused by inaccuracies in tho numerical integration schemo used in the computer code. (Information received from R. Rundborg, Los Alamos National Laboratory, 1987.) 


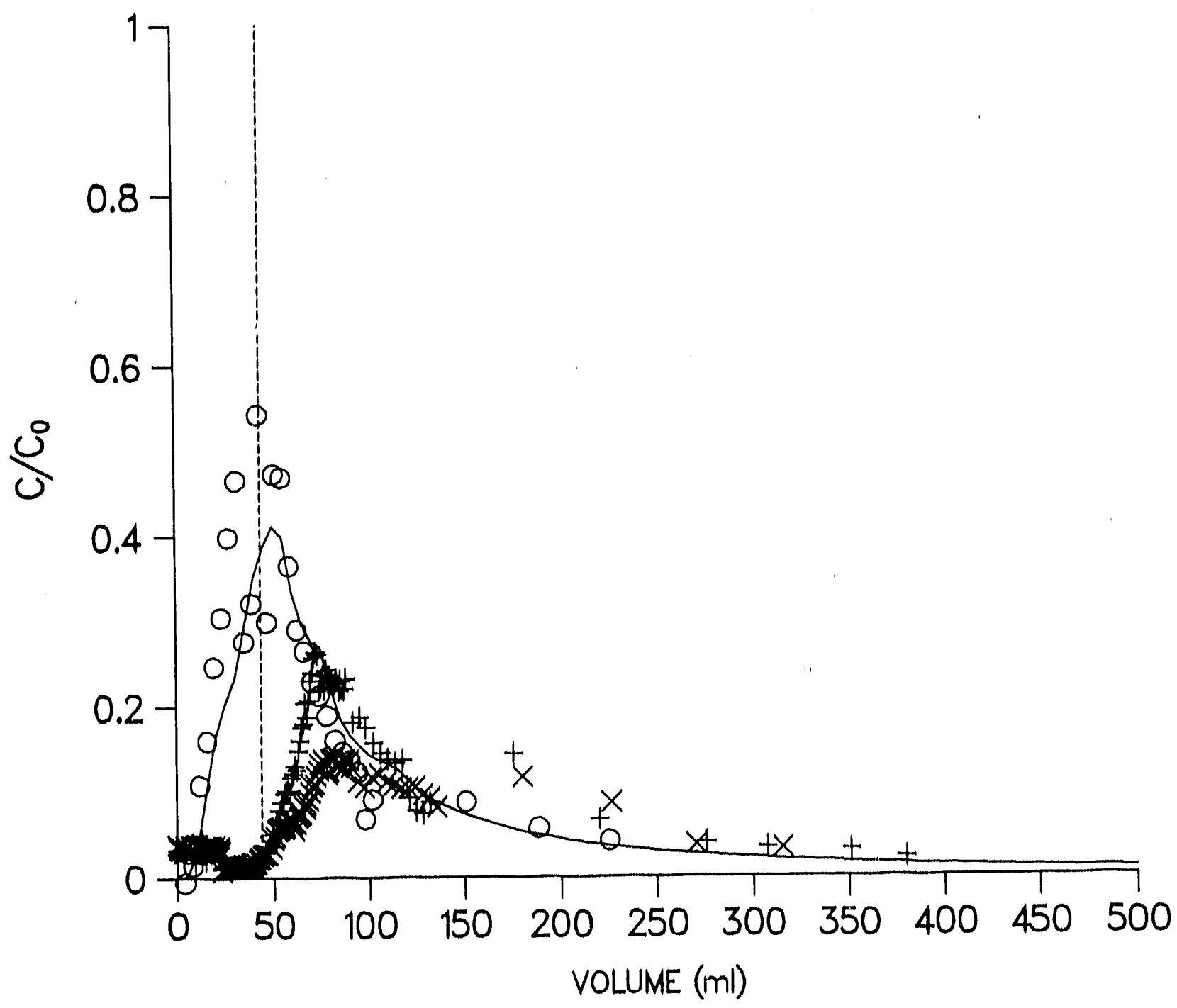

Yig. 20. Model for H'TO tracer olution through a single parallel-sidod fracture in a porous modium uses the parumetors for model 5 in 'T'uble II. Model paramotors are identical to those used for Fig. 23 except tracer diffusivity was changed to that of HTO. Dashed line indicates change to unspiked J-13 water. Irregularitios in olution curve shapes in those modols are probably caused by inaccuracies in tho numerical integration schomo used in the computer code. (Information received from R. Rundberg, Los Alamos National Laboratory, 1087.) 

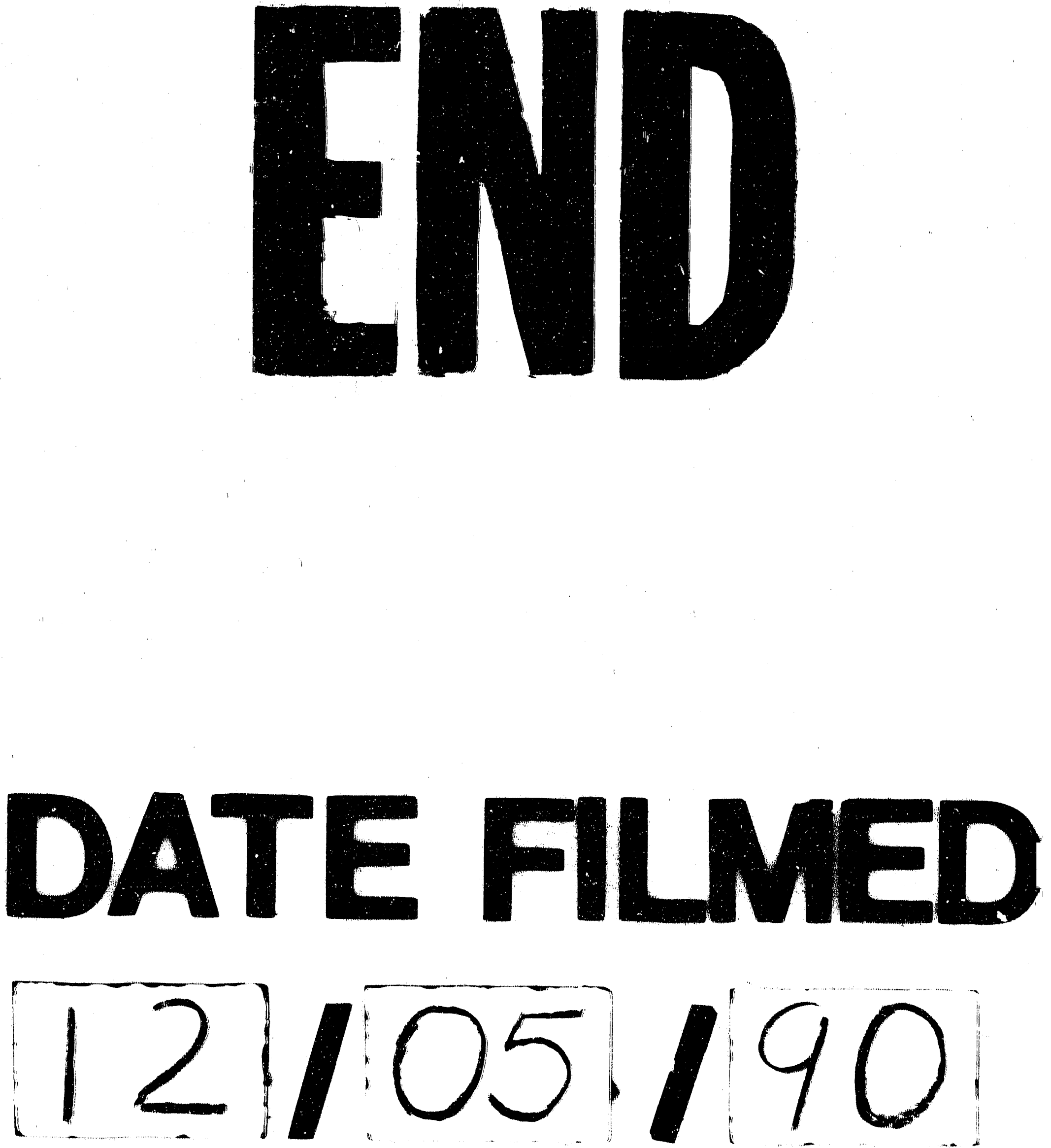
